\title{
Freshwater monitoring by nanopore sequencing
}

3 Lara Urban ${ }^{1 \$^{*}}$, Andre Holzer ${ }^{2 *}$, J Jotautas Baronas ${ }^{3}$, Michael Hall ${ }^{1}$, Philipp Braeuninger-Weimer ${ }^{4}$, Michael J

4 Scherm $^{5}$, Daniel J Kunz ${ }^{6,7}$, Surangi N Perera ${ }^{8}$, Daniel E Martin-Herranz ${ }^{1}$, Edward T Tipper ${ }^{3}$, Susannah J Salter ,

5 and Maximilian R Stammnitz ${ }^{9 *}$

6

$7 \quad{ }^{I}$ European Bioinformatics Institute, Wellcome Genome Campus, Hinxton CB10 1SD, UK;

$8 \quad{ }^{2}$ Department of Plant Sciences, University of Cambridge, Cambridge CB2 3EA, UK;

$9{ }^{3}$ Department of Earth Sciences, University of Cambridge, Cambridge CB2 3EQ, UK;

$10{ }^{4}$ Department of Engineering, University of Cambridge, Cambridge CB3 OFA, UK;

11 Department of Biochemistry, University of Cambridge, Cambridge CB2 1GA, UK;

$12{ }^{6}$ Wellcome Sanger Institute, Wellcome Trust Genome Campus, Hinxton CB10 1SA, UK;

$13{ }^{7}$ Department of Physics, University of Cambridge, Cambridge CB3 OHE, UK;

$14{ }^{8}$ Department of Physiology, Development \& Neuroscience, University of Cambridge, Cambridge CB2 3DY, UK;

$15{ }^{9}$ Department of Veterinary Medicine, University of Cambridge, Cambridge CB3 OES, UK;

$17 \S$ These authors contributed equally * To whom correspondence should be addressed: maxrupsta@gmail.com; andre.holzer.biotech@gmail.com; lara.h.urban@gmail.com

Key words: Nanopore sequencing, environmental metagenomics, freshwater ecology, portable bacterial

ORCID IDs: Lara Urban: 0000-0002-5445-9314, Andre Holzer: 0000-0003-2439-6364, J Jotautas Baronas: 0000-0002-4027-3965, Michael Hall: 0000-0003-3683-6208, Philipp Braeuninger-Weimer: 0000-0001-86771647, Michael J Scherm: 0000-0002-3289-9159, Daniel J Kunz: 0000-0003-3597-6591, Surangi N Perera: 00000003-4827-9242, Daniel E Martin-Herranz: 0000-0002-2285-3317, Edward T Tipper: 0000-0003-3540-3558, 


\section{ABSTRACT}

32 While traditional microbiological freshwater tests focus on the detection of specific bacterial indicator species,

33 including pathogens, direct tracing of all aquatic DNA through metagenomics poses a profound alternative. Yet,

34 in situ metagenomic water surveys face substantial challenges in cost and logistics. Here we present a simple, fast,

35 cost-effective and remotely accessible freshwater diagnostics workflow centred around the portable nanopore

36 sequencing technology. Using defined compositions and spatiotemporal microbiota from surface water of an

37 example river in Cambridge (UK), we provide optimised experimental and bioinformatics guidelines, including a

38 benchmark with twelve taxonomic classification tools for nanopore sequences. We find that nanopore

39 metagenomics can depict the hydrological core microbiome and fine temporal gradients in line with

40 complementary physicochemical measurements. In a public health context, these data feature relevant sewage

41 signals and pathogen maps at species level resolution. We anticipate that this framework will gather momentum

42 for new environmental monitoring initiatives using portable devices.

\section{INTRODUCTION}

45 The global assurance of safe drinking water and basic sanitation has been recognised as a United Nations

46 Millennium Development Goal (Bartram, Lewis, Lenton, \& Wright, 2005), particularly in light of the pressures

47 of rising urbanisation, agricultural intensification and climate change (Haddeland et al., 2014; Schewe et al.,

48 2014). Waterborne diseases represent a particular global threat, with zoonotic diseases such as typhoid fever, cholera or leptospirosis resulting in hundreds of thousands of deaths each year (Prüss-Üstün, Kay, Fewtrell, \& Bartram, 2002; Prüss-Üstün et al., 2019).

To control for risks of infection by waterborne diseases, microbial assessments can be conducted. While traditional microbial tests focus on the isolation of specific bacterial indicator organisms through selective media outgrowth in a diagnostic laboratory, this cultivation process is all too often time consuming, infrastructure-dependent and lacks behind in automatisation (Salazar \& Sunagawa, 2017; Tringe \& Rubin, 2005). Environmental metagenomics, the direct tracing of DNA from environmental samples, constitutes a less organism-tailored, datadriven monitoring alternative. Such approaches have been demonstrated to provide robust measurements of relative taxonomic species composition as well as functional diversity in a variety of environmental contexts 
bioRxiv preprint doi: https://doi org/10.1101/2020.02 06.936302; this version posted November 18, 2020. The copyright holder for this preprint (which was not certified by peer review) is the author/funder, who has granted bioRxiv a license to display the preprint in perpetuity. It is made available under aCC-BY-NC-ND 4.0 International license.

common to culturing (Salazar \& Sunagawa, 2017; Tringe \& Rubin, 2005). However, they usually depend on expensive stationary equipment, specialised operational training and substantial time lags between fieldwork, sample preparation, raw data generation and access. Combined, there is an increasing demand for freshwater monitoring frameworks that unite the advantages of metagenomic workflows with high cost effectiveness, fast technology deployability and data transparency (Gardy \& Loman, 2018).

In recent years, these challenges have been revisited with the prospect of mobile DNA analysis. The main driver of this is the 'portable' MinION device from Oxford Nanopore Technologies (ONT), which enables real-time DNA sequencing using nanopores (Jain, Olsen, Paten, \& Akeson, 2016). Nanopore read lengths can be comparably long, currently up to $\sim 2 * 10^{6}$ bases (Payne, Holmes, Rakyan, \& Loose, 2018), which is enabled by continuous electrical sensing of sequential nucleotides along single DNA strands. In connection with a laptop for the translation of raw voltage signal into nucleotides, nanopore sequencing can be used to rapidly monitor long DNA sequences in remote locations. Although there are still common concerns about the technology's base-level accuracy, mobile MinION setups have already been transformative for real-time tracing and rapid data sharing during bacterial and viral pathogen outbreaks (Boykin et al., 2019; Chan et al., 2020; Faria et al., 2018; Faria et al., 2017; Kafetzopoulou et al., 2019; Quick et al., 2015; Quick et al., 2016). In the context of freshwater analysis, a MinION whole-genome shotgun sequencing protocol has recently been leveraged for a comparative study of 11 rivers (Reddington et al., 2020). This report highlights key challenges which emerge in serial monitoring scenarios of a relatively low-input DNA substrate (freshwater), for example large sampling volumes (2-4 litres) and small shotgun fragments (mean $<4 \mathrm{kbp}$ ). We reasoned that targeted DNA amplification may be a suitable means to bypass these bottlenecks and assess river microbiomes with nanopore sequencing.

Here we report a simple, cost-effective workflow to assess and monitor microbial freshwater ecosystems with targeted nanopore DNA sequencing. Our benchmarking study involves the design and optimisation of essential experimental steps for multiplexed MinION usage in the context of local environments, together with an evaluation of computational methods for the bacterial classification of nanopore sequencing reads from metagenomic libraries. To showcase the resolution of sequencing-based aquatic monitoring in a spatiotemporal setting, we combine DNA analyses with physicochemical measurements of surface water samples collected at nine locations within a confined $\sim 12$ kilometre reach of the River Cam passing through the city of Cambridge (UK) in April, June and August 2018. 
bioRxiv preprint doi: https://doi org/10.1101/2020.02 $06.936302 ;$ this version posted November $18,2020$. The copyright holder for this preprint (which was not certified by peer review) is the author/funder, who has granted bioRxiv a license to display the preprint in perpetuity. It is made available under aCC-BY-NC-ND 4.0 International license.

RESULTS

\section{Experimental design and computational workflows}

93 Using a bespoke workflow, nanopore full-length (V1-V9) 16S ribosomal RNA (rRNA) gene sequencing was

94 performed on all location-barcoded freshwater samples at each of the three time points (Figure 1; Supplementary

95 Table 1; Material and Methods). River isolates were multiplexed with negative controls (deionised water) and

96 mock community controls composed of eight bacterial species in known mixture proportions.

97

a
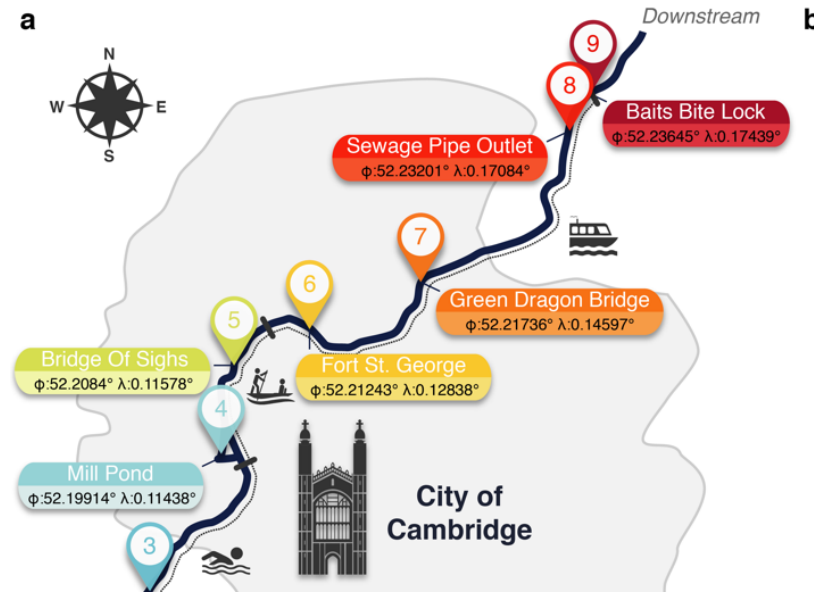

City of Cambridge

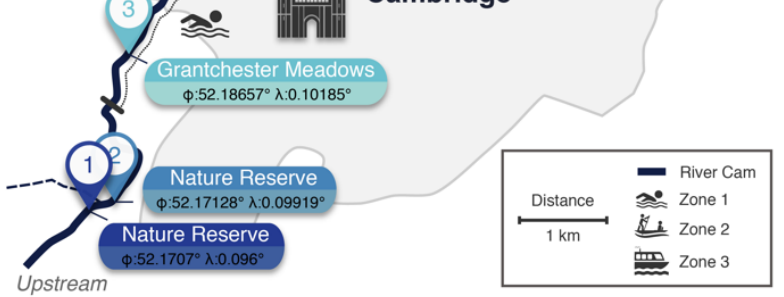

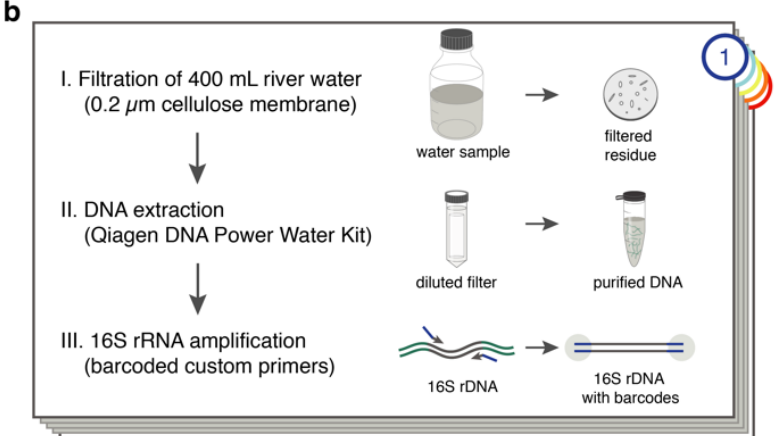

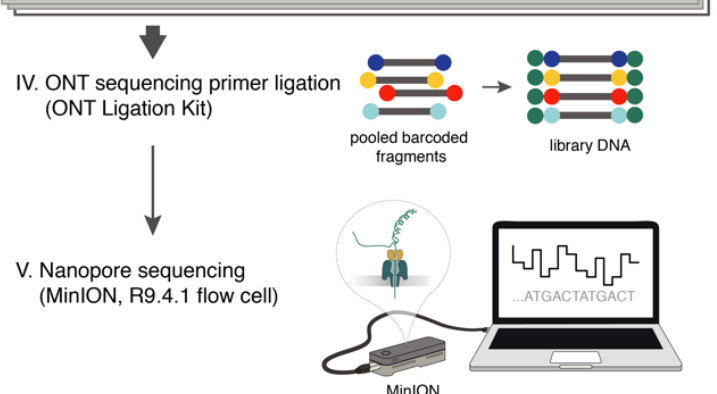

Figure 1: Freshwater microbiome study design and experimental setup. (a) Schematic map of Cambridge (UK), illustrating sampling locations (colour-coded) along the River Cam. Geographic coordinates of latitude and longitude are expressed as decimal fractions according to the global positioning system. (b) Laboratory workflow to monitor bacterial communities from freshwater samples using nanopore sequencing (Material and Methods).

To obtain valid taxonomic assignments from freshwater sequencing profiles using nanopore sequencing, twelve different classification tools were compared through several performance metrics (Figure 2; Supplementary Figure 1; Material and Methods). Our comparison included established classifiers such as RDP (Wang, Garrity, Tiedje, \& Cole, 2007), Kraken (Wood \& Salzberg, 2014) and Centrifuge (Kim, Song, Breitwieser, \& Salzberg, 2016), as well as more recently developed methods optimised for higher sequencing error rates such as IDTAXA (Murali, Bhargava, \& Wright, 2018) and Minimap2 (Li, 2018). An Enterobacteriaceae overrepresentation was observed across all replicates and classification methods, pointing towards a consistent Escherichia coli amplification bias

111 potentially caused by skewed taxonomic specificities of the selected $16 \mathrm{~S}$ primer pair $27 \mathrm{f}$ and $1492 \mathrm{r}$ (Frank et al., 
bioRxiv preprint doi: https://doi.org/10.1101/2020.02.06.936302; this version posted November 18, 2020. The copyright holder for this preprint (which was not certified by peer review) is the author/funder, who has granted bioRxiv a license to display the preprint in perpetuity. It is made available under aCC-BY-NC-ND 4.0 International license.

112 2008) (Figure 2b). Root mean square errors (RMSE) between observed and expected bacteria of the mock

113 community differed slightly across all classifiers (Figure 2c). Robust quantifications were obtained by Minimap2

114 alignments against the SILVA v.132 database (Quast et al., 2013), for which 99.68 \% of classified reads aligned

115 to the expected mock community taxa (mean sequencing accuracy $92.08 \%$ ). Minimap2 classifications reached

116 the second lowest RMSE (excluding Enterobacteriaceae), and relative quantifications were highly consistent

117 between mock community replicates. Benchmarking of the classification tools on one aquatic sample further

118 confirmed Minimap2's reliable performance in a complex bacterial community (Figure 2d), although other tools

119 such as MAPseq (Matias Rodrigues, Schmidt, Tackmann, \& von Mering, 2017), SPINGO (Allard, Ryan, Jeffery,

120 \& Claesson, 2015), or IDTAXA also produced highly concordant results - despite variations in memory usage

121 and runtime over several orders of magnitude (Supplementary Figure 1).

122

a

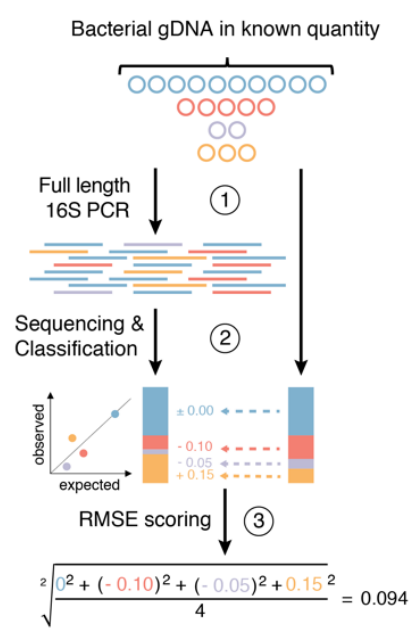

b
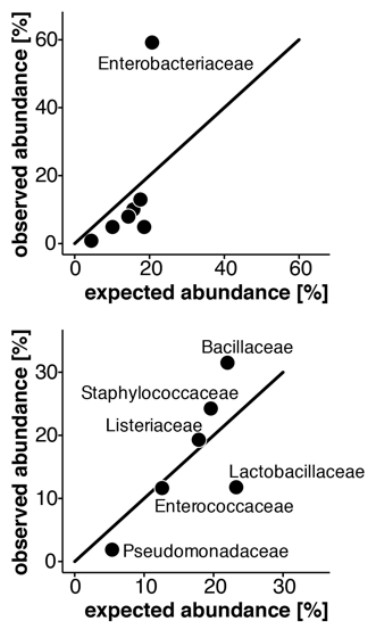

C

\begin{tabular}{|c|c|c|c|c|c|c|c|c|c|c|c|c|c|}
\hline Pseudomonadaceae & 4.2 & 0.7 & 0.7 & 0.8 & 0.7 & 0.7 & 0.7 & 0.7 & 0.7 & 4.1 & 0.7 & 1.0 & 0.8 \\
\hline Enterobacteriaceae & 20.5 & 58.8 & 59.1 & 59.9 & 59.7 & 60.0 & 59.6 & 60.4 & 59.9 & 48.2 & 59.9 & 60.4 & 67.0 \\
\hline Lactobacillaceae & 18.4 & 4.9 & 4.8 & 4.7 & 4.7 & 4.7 & 4.6 & 4.7 & 4.6 & 9.4 & 4.8 & 5.0 & 1.8 \\
\hline Enterococcaceae & 9.9 & 4.8 & 4.7 & 4.8 & 4.5 & 4.6 & 4.8 & 4.5 & 4.6 & 10.7 & 3.0 & 3.9 & 1.8 \\
\hline Staphylococcaceae & 15.5 & 10.1 & 9.9 & 9.6 & 9.8 & 9.8 & 9.8 & 9.7 & 9.7 & 4.5 & 9.4 & 11.1 & 8.7 \\
\hline Listeriaceae & 14.1 & 8.0 & 7.9 & 7.2 & 7.7 & 7.1 & 7.4 & 6.9 & 6.7 & 4.2 & 4.0 & 1.6 & 2.0 \\
\hline Bacillaceae & 17.4 & 12.8 & 12.9 & 13.0 & 13.0 & 13.1 & 13.2 & 13.2 & 13.9 & 19.0 & 18.1 & 17.1 & 18.1 \\
\hline RMSE & 0.00 & 15.91 & 16.04 & 16.38 & 16.30 & 16.42 & 16.25 & 16.57 & 16.41 & 12.36 & 16.63 & 16.87 & 19.68 \\
\hline RMSE reduced & 0.00 & 6.52 & 6.57 & 6.75 & 6.78 & 6.88 & 6.95 & 7.04 & 7.53 & 9.38 & 11.42 & 11.78 & 16.58 \\
\hline \multicolumn{14}{|l|}{ RMSE_reduced } \\
\hline
\end{tabular}

d Comparison to majority vote $\square$ overlapping $\square$ non overlapping $\square$ not in majority $\square$ unclassified

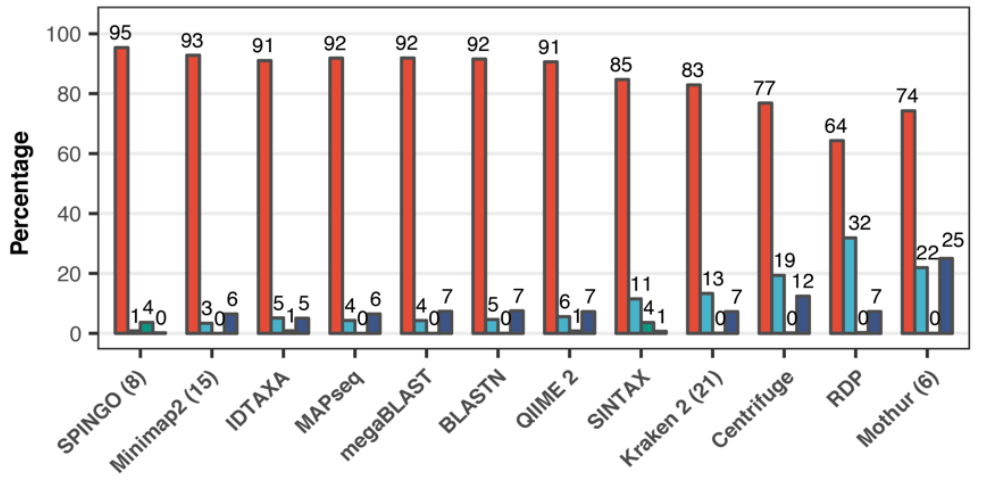


bioRxiv preprint doi: https://doi.org/10.1101/2020.02 06.936302; this version posted November 18, 2020. The copyright holder for this preprint (which was not certified by peer review) is the author/funder, who has granted bioRxiv a license to display the preprint in perpetuity. It is made available under aCC-BY-NC-ND 4.0 International license.

127 representation of Minimap2 (kmer length 15) quantifications with (upper) and without (lower) Enterobacteriaceae 128 (Material and Methods). (c) Mock community classification output summary for twelve classification tools tested 129 against the same 10,000 reads. Root mean squared errors observed and expected bacterial read fractions are 130 provided with (RMSE) and without Enterobacteriaceae (RMSE reduced). (d) Classification output summary for 131 10,000 reads randomly drawn from an example freshwater sample (Material and Methods). 'Overlapping' 132 fractions (red) represent agreements of a classification tool with the majority of tested methods on the same reads, 133 while 'non-overlapping' fractions (light blue) represent disagreements. Dark green sets highlight rare taxon 134 assignments not featured in any of the 10,000 majority classifications, while dark blue bars show unclassified read 135 fractions.

\section{Diversity analysis and river core microbiome}

138 Using Minimap2 classifications within our bioinformatics consensus workflow (Supplementary Figure 2; Material 139 and Methods), we then inspected sequencing profiles of three independent MinION runs for a total of 30 river 140 DNA isolates and six controls. This yielded $\sim 8.3$ million sequences with exclusive barcode assignments (Figure

141 3a; Supplementary Table 2). Overall, $82.9 \%(n=6,886,232)$ of raw reads could be taxonomically assigned to the 142 family level (Figure 3b). To account for variations in sample sequencing depth, rarefaction with a cut-off at 37,000 143 reads was applied to all samples. While preserving $90 \%$ of the original family level taxon richness (Mantel test,

$144 \mathrm{R}=0.814, \mathrm{p}=2.1 * 10^{-4}$; Supplementary Figure 3), this conservative thresholding resulted in the exclusion of 14 145 samples, mostly from the June time point, for subsequent high-resolution analyses. The 16 remaining surface 146 water samples revealed moderate levels of microbial heterogeneity (Figure 3b; Supplementary Figure 3): 147 microbial family alpha diversity ranged between 0.46 (June-6) and 0.92 (April-7) (Simpson index), indicating 148 low-level evenness with a few taxonomic families that account for the majority of the metagenomic signal. 
bioRxiv preprint doi: https://doi.org/10.1101/2020.02.06.936302; this version posted November 18, 2020. The copyright holder for this preprint (which was not certified by peer review) is the author/funder, who has granted bioRxiv a license to display the preprint in perpetuity. It is made available under aCC-BY-NC-ND 4.0 International license.

a

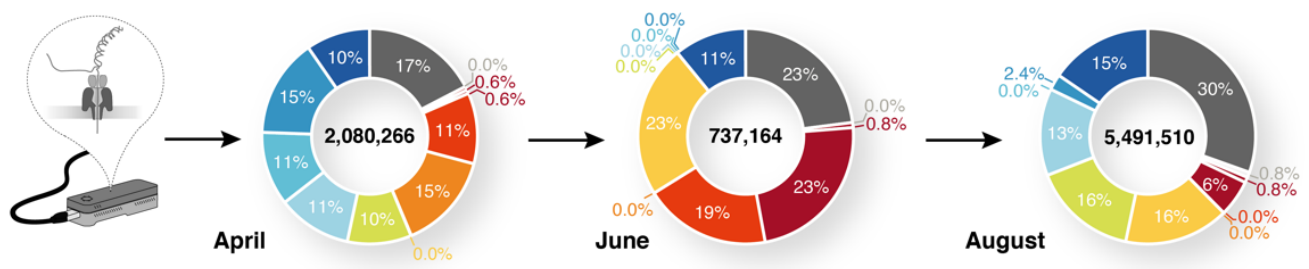

Barcodes

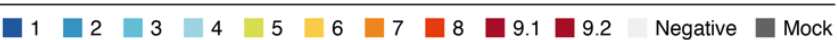
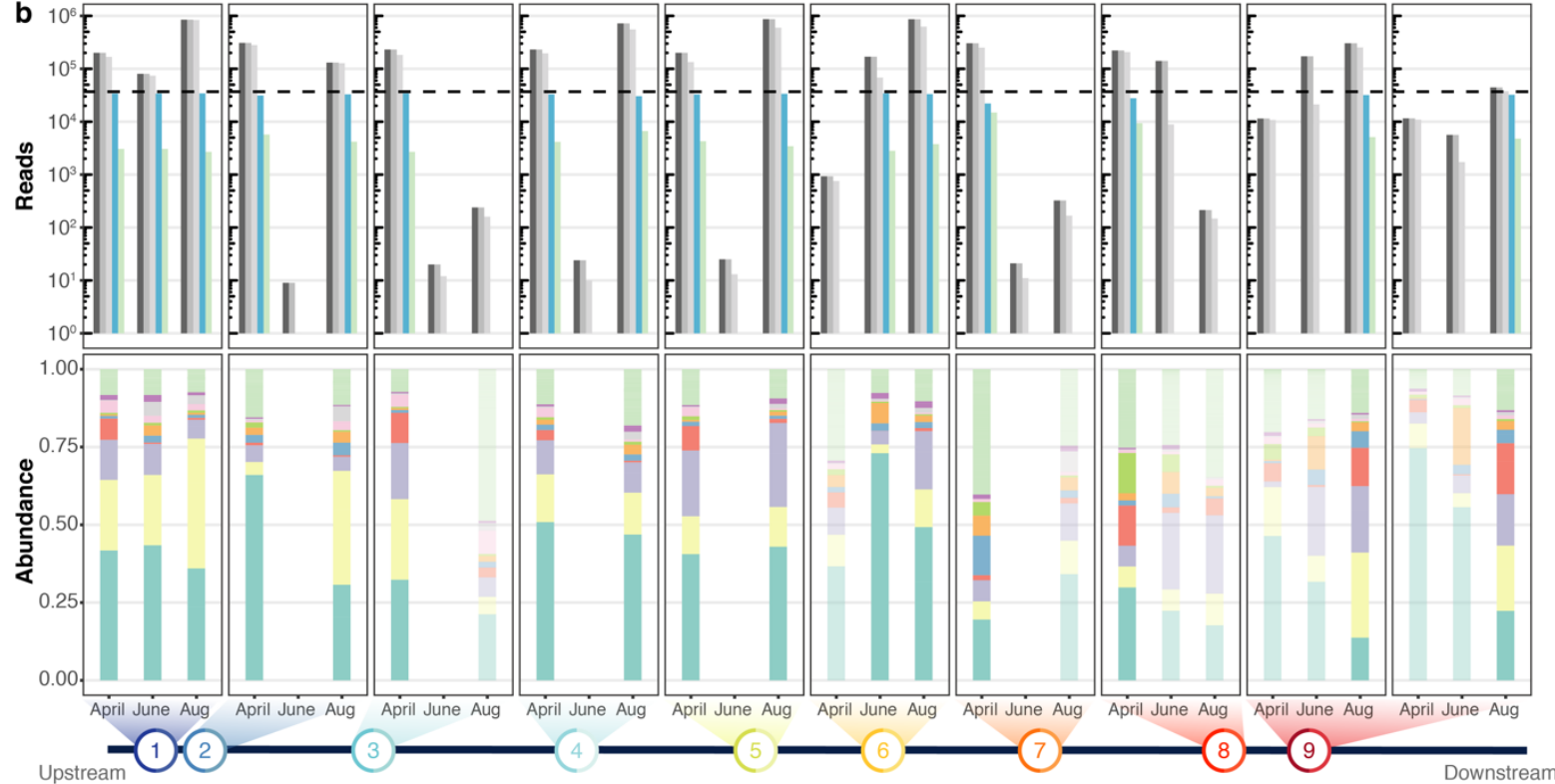

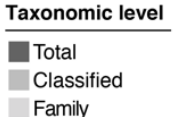

Classified

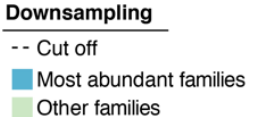

Other families

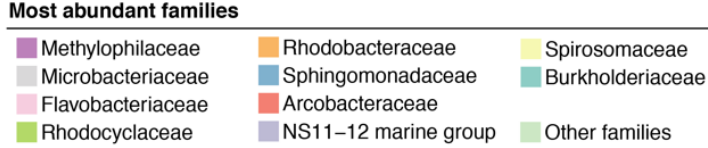

160 Hierarchical clustering of taxon profiles showed a dominant core microbiome across all aquatic samples (clusters

$161 \mathrm{C} 2$ and $\mathrm{C} 4$, Figure 4a). The most common bacterial families observed were Burkholderiaceae (40.0 \%),

Figure 3: Bacterial diversity of the River Cam. (a) Nanopore sequencing output summary. Values in the centre of the pie charts depict total numbers of classified nanopore sequences per time point. Percentages illustrate representational fractions of locations and control barcodes (negative control and mock community). (b) Read depth and bacterial classification summary. Upper bar plot shows the total number of reads, and the number of reads classified to any taxonomic level, to at least bacterial family level, to the ten most abundant bacterial families across all samples, or to other families. Rarefaction cut-off displayed at 37,000 reads (dashed line). Lower bar plot features fractions of the ten most abundant bacterial families across the samples with more than 100 reads. Colours in bars for samples with less than 37,000 reads are set to transparent.

Spirosomaceae (17.7\%), and NS11-12 marine group (12.5\%), followed by Arcobacteraceae (4.8 \%), Sphingomonadaceae (2.9\%) and Rhodobacteraceae (2.5\%) (Figure 4b). Members of these families are commonly associated with aquatic environments; for example, major fractions of Burkholderiaceae reads originated from genera such as Limnohabitans, Rhodoferax, Polynucleobacter or Aquabacterium (Supplementary Figure 4), which validates the suitability of this nanopore metagenomics workflow. Hierarchical clustering 
167 additionally showed that two biological replicates collected at the same location and time point (April samples

1689.1 and 9.2), grouped with high concordance; this indicates that spatiotemporal trends are discernible even within

169 a highly localised context.

170 
bioRxiv preprint doi: https://doi.org/10.1101/2020.02 06.936302; this version posted November 18, 2020. The copyright holder for this preprint (which was not certified by peer review) is the author/funder, who has granted bioRxiv a license to display the preprint in perpetuity. It is made available under aCC-BY-NC-ND 4.0 International license.
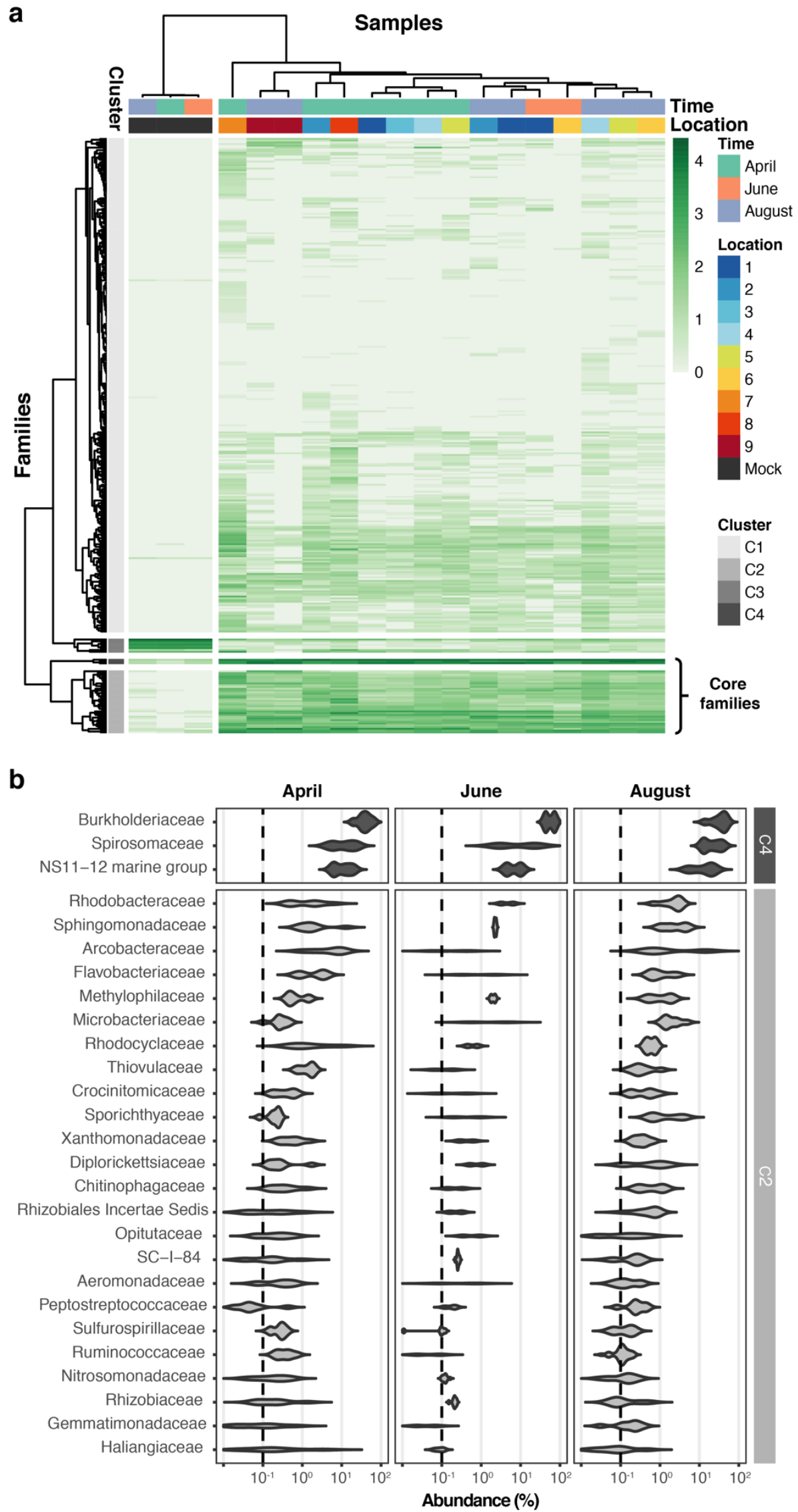

Figure 4: Core microbiome of the River Cam. (a) Hierarchical clustering of bacterial family abundances across 
bioRxiv preprint doi: https://doi.org/10.1101/2020.02 06.936302; this version posted November 18, 2020. The copyright holder for this preprint (which was not certified by peer review) is the author/funder, who has granted bioRxiv a license to display the preprint in perpetuity. It is made available under aCC-BY-NC-ND 4.0 International license.

175 families, one (C3) corresponding to the main mock community families and one (C1) corresponding to the 176 majority of rare accessory taxa. (b) Detailed river core microbiome. Violin plots summarise fractional representation of bacterial families from clusters $\mathrm{C} 2$ and $\mathrm{C} 4\left(\log _{10}\right.$ scale of relative abundance [\%] across all

178 samples, $\mathrm{n}_{\text {April }}=7, \mathrm{n}_{\mathrm{June}}=2, \mathrm{n}_{\text {August }}=7$ ), sorted by median total abundance. Vertical dashed lines depict $0.1 \%$ 179 proportion.

180

181 Besides the dominant core microbiome, microbial profiles showed a marked arrangement of time dependence,

182 with water samples from April grouping more distantly to those from June and August. Principal component analysis (PCA) illustrates the seasonal divergence among the three sampling months (Figure 5a; Supplementary

184 Figure 5). The strongest differential abundances along the chronological axis of variation (PC3) derived from Carnobacteriaceae (Figure 5b), a trend also highlighted by taxon-specific log-normal mixture model decomposition between the two seasons (April vs. June/August; $\mathrm{p}<0.01$; Material and Methods). Indeed, members of this bacterial family have been primarily isolated from cold substrates (Lawson \& Caldwell, 2014).

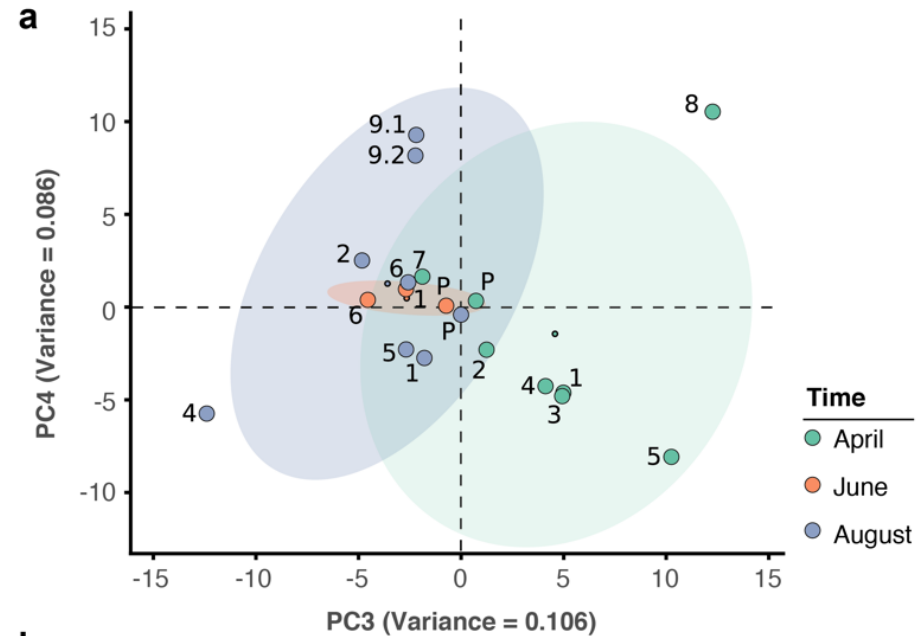

b
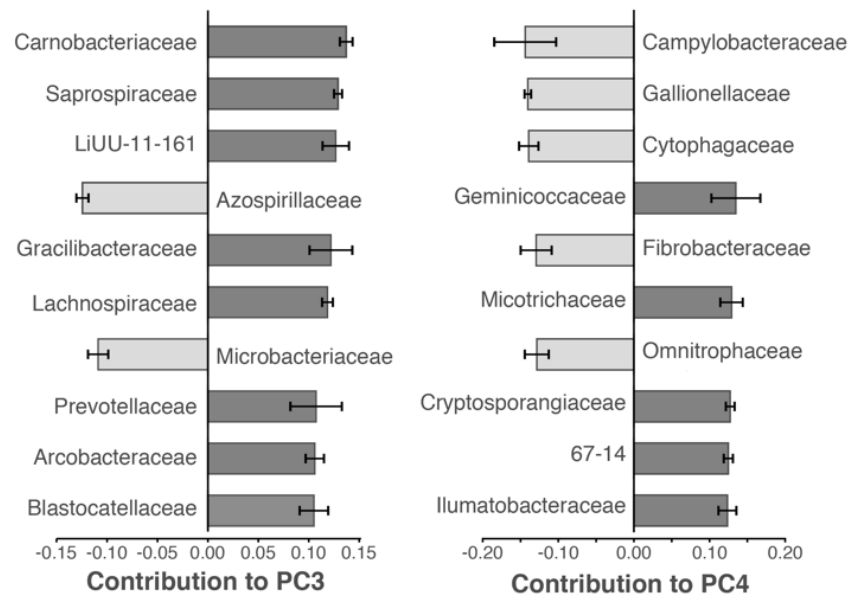

190 Figure 5: Spatiotemporal axes of taxonomic diversity in the River Cam. (a) PCA of bacterial composition 
193 hoc Mann-Whitney U rank test (April vs. August): $p=2.2 * 10^{-3}$. (b) Contribution of individual bacterial families

194 to the PCs in (a). Error bars represent the standard deviation of these families across four independent rarefactions.

\section{Hydrochemistry and seasonal profile of the River Cam}

197 While a seasonal difference in bacterial composition can be expected due to increasing water temperatures in the

198 summer months, additional changes may have also been caused by alterations in river hydrochemistry and flow

199 rate (Figure 6a; Supplementary Figure 6; Supplementary Table 1). To assess this effect in detail, we measured the

$200 \mathrm{pH}$ and a range of major and trace cations in all river water samples using inductively coupled plasma-optical

201 emission spectroscopy (ICP-OES), as well as major anions using ion chromatography (Material and Methods).

202 As with the bacterial composition dynamics, we observed significant temporal variation in water chemistry,

203 superimposed on a spatial gradient of generally increasing sodium and chloride concentrations along the river

204 reach (Figure 6b-c). This spatially consistent effect is likely attributed to wastewater and agricultural discharge

205 inputs in and around Cambridge city. A comparison of the major element chemistry in the River Cam transect

206 with the world's 60 largest rivers further corroborates the likely impact of anthropogenic pollution in this fluvial ecosystem (Gaillardet, Dupré, Louvat, \& Allègre, 1999) (Figure 6d; Material and Methods). 
a

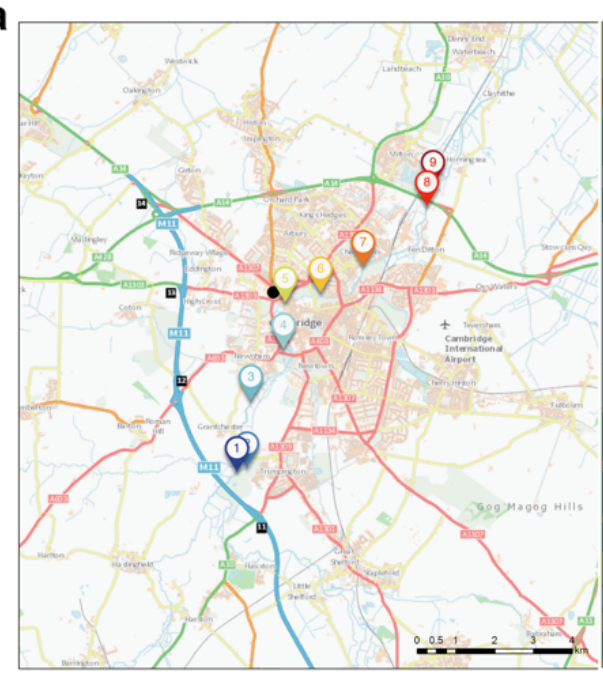

b

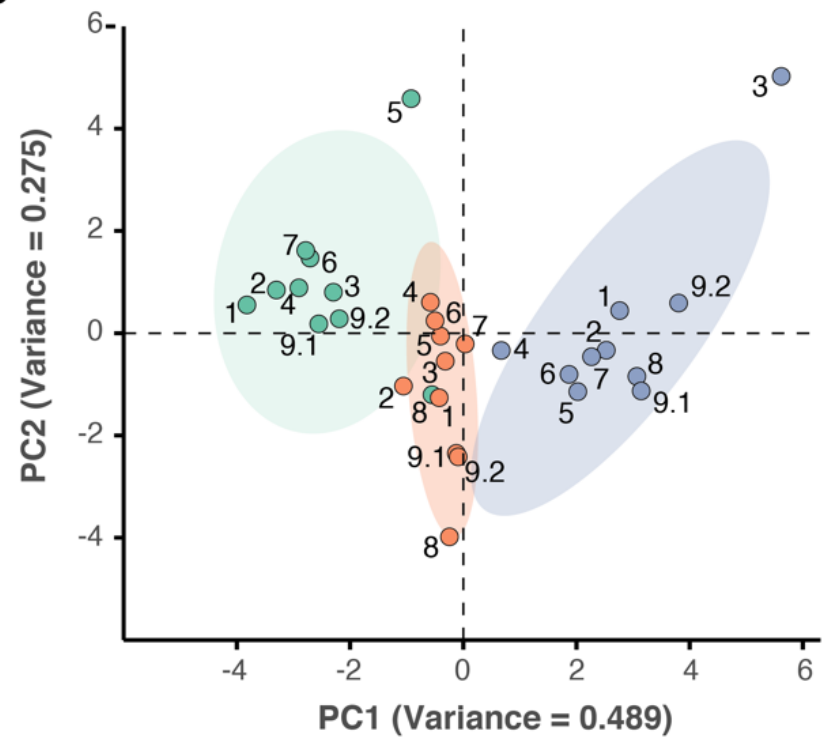

\section{Bedrock geology}

$\square$ sandstone

chalk

chalk

chalk

$\square$ chalk

$\square$ mudstone

chalk

mudstone

\section{Superficial deposits}

\begin{tabular}{l}
\hline$\square$ sand \& gravel \\
$\square$ diamicton \\
$\square$ diamicton \\
$\square$ clay, slit, sand \& gravel \\
$\square$ clay, slit, sand \& gravel \\
$\square$ sand \& gravel \\
$\square$ clay, slit, sand \& gravel \\
peat \\
sand \& gravel
\end{tabular}

sand \& grave

\section{d}
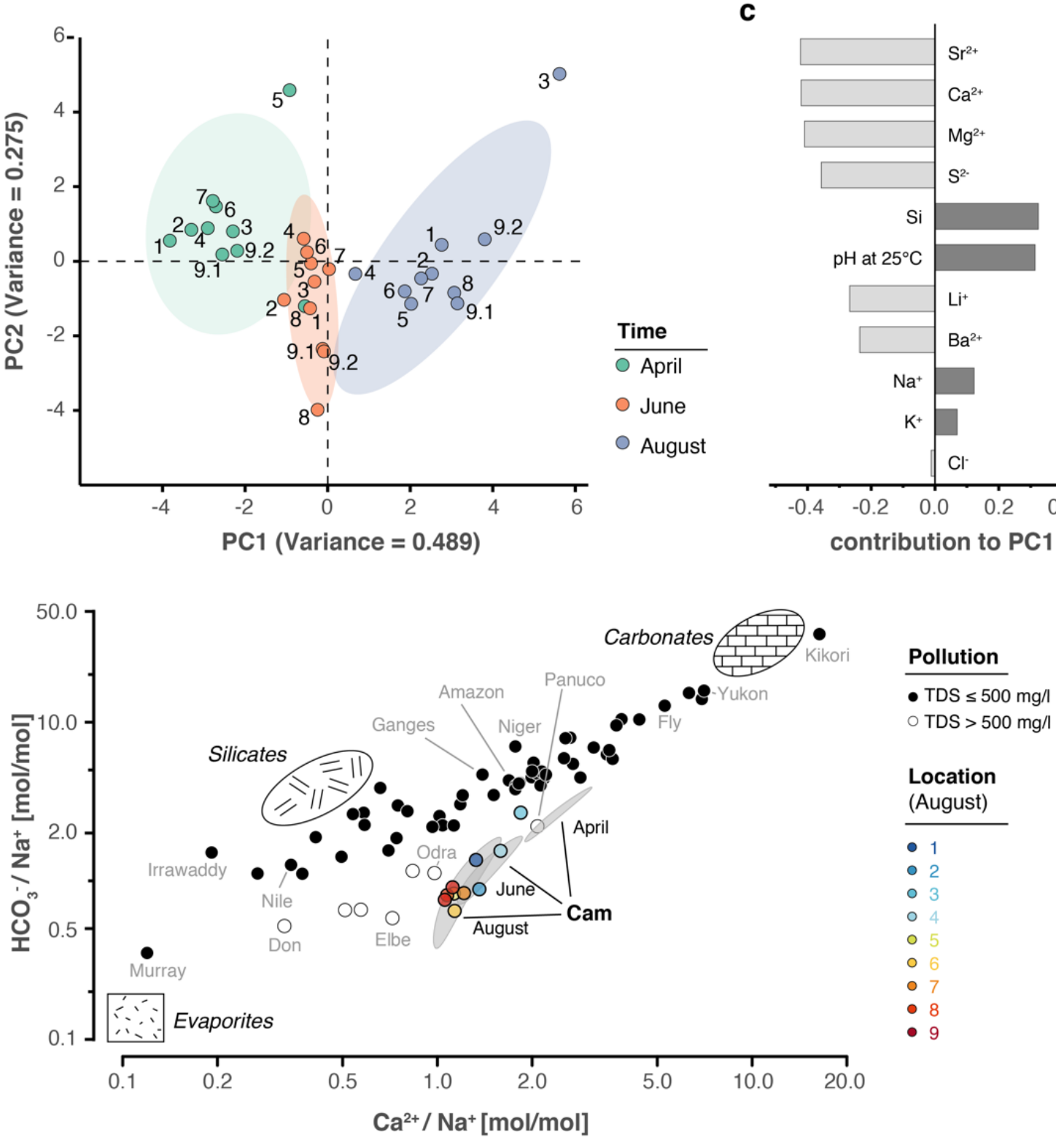

c

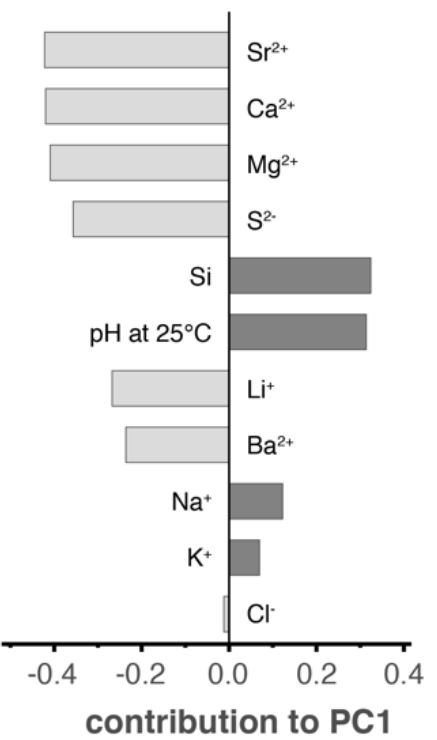

210 Figure 6: Geological and hydrochemical profile of the River Cam and its basin. (a) Outline of the Cam River 211 catchment surrounding Cambridge (UK), and its corresponding lithology. Overlay of bedrock geology and 
bioRxiv preprint doi: https://doi.org/10.1101/2020.02.06.936302; this version posted November 18, 2020. The copyright holder for this preprint (which was not certified by peer review) is the author/funder, who has granted bioRxiv a license to display the preprint in perpetuity. It is made available under aCC-BY-NC-ND 4.0 International license.

superficial deposits (British Geological Survey data: DiGMapGB-50, 1:50,000 scale) is shown as visualised by GeoIndex. Bedrock is mostly composed of subtypes of Cretaceous limestone (chalk), gault (clay, sand) and mudstone. Approximate sampling locations are colour-coded as in Figure 1. (b) Principal component analysis of measured $\mathrm{pH}$ and 13 inorganic solute concentrations of this study's 30 river surface water samples. PC1 ( 49 \% variance) displays a strong, continuous temporal shift in hydrochemistry. (c) Parameter contributions to PC1 in (b), highlighting a reduction in water hardness $\left(\mathrm{Ca}^{2+}, \mathrm{Mg}^{2+}\right)$ and increase in $\mathrm{pH}$ towards the summer months (June and August). (d) Mixing diagram with $\mathrm{Na}^{+}$-normalised molar ratios, representing inorganic chemistry loads of the world's 60 largest rivers; open circles represent polluted rivers with total dissolved solid (TDS) concentrations $>500 \mathrm{mg} \mathrm{l}^{-1}$. Cam River ratios are superimposed as ellipses from ten samples per month $(50 \%$ confidence, respectively). Separate data points for all samples from August are also shown and colour-coded, indicating the upstream-to-downstream trend of $\mathrm{Na}^{+}$increase (also observed in April and June). End-member signatures show typical chemistry of small rivers draining these lithologies exclusively (carbonate, silicate and evaporite).

\section{Maps of potential bacterial pathogens at species level resolution}

Freshwater sources throughout the United Kingdom have been notorious for causing bacterial infections such as leptospirosis (Public Health England, 2016, 2019). In line with the physicochemical profile of the River Cam, we therefore next determined the spatiotemporal enrichment of potentially important functional bacterial taxa through nanopore sequencing. We retrieved 55 potentially pathogenic bacterial genera through integration of species known to affect human health (Jin et al., 2018; Wattam et al., 2017), and also 13 wastewater-associated bacterial genera (Wu et al., 2019) (Supplementary Table 3). Of these, 21 potentially pathogenic and eight wastewaterassociated genera were detected across all of the river samples (Figure 7; Material and Methods). Many of these signals were stronger downstream of urban sections, within the mooring zone for recreational and residential barges (location 7; Figure 1a) and in the vicinity of sewage outflow from a nearby wastewater treatment plant (location 8). The most prolific candidate pathogen genus observed was Arcobacter, which features multiple species implicated in acute gastrointestinal infections (Kayman et al., 2012).

In general, much of the taxonomic variation across all samples was caused by sample April-7 (PC1 explains 27.6 $\%$ of the overall variance in bacterial composition; Supplementary Figure 5a-b). Its profile was characterised by an unusual dominance of Caedibacteraceae, Halomonadaceae and others (Supplementary Figure 5c). Isolate April-8 also showed a highly distinct bacterial composition, with some families nearly exclusively occurring in this sample (outlier analysis; Material and Methods). The most predominant bacteria in this sewage pipe outflow are typically found in wastewater sludge or have been shown to contribute to nutrient pollution from effluents of wastewater plants, such as Haliangiaceae, Nitospiraceae, Rhodocyclaceae, and Saprospiracea (Nielsen, Saunders, Hansen, Larsen, \& Nielsen, 2012; Wu et al., 2019) (Figure 7). 
bioRxiv preprint doi: https://doi.org/10.1101/2020.02.06.936302; this version posted November 18, 2020. The copyright holder for this preprint (which was not certified by peer review) is the author/funder, who has granted bioRxiv a license to display the preprint in perpetuity. It is made available under aCC-BY-NC-ND 4.0 International license.

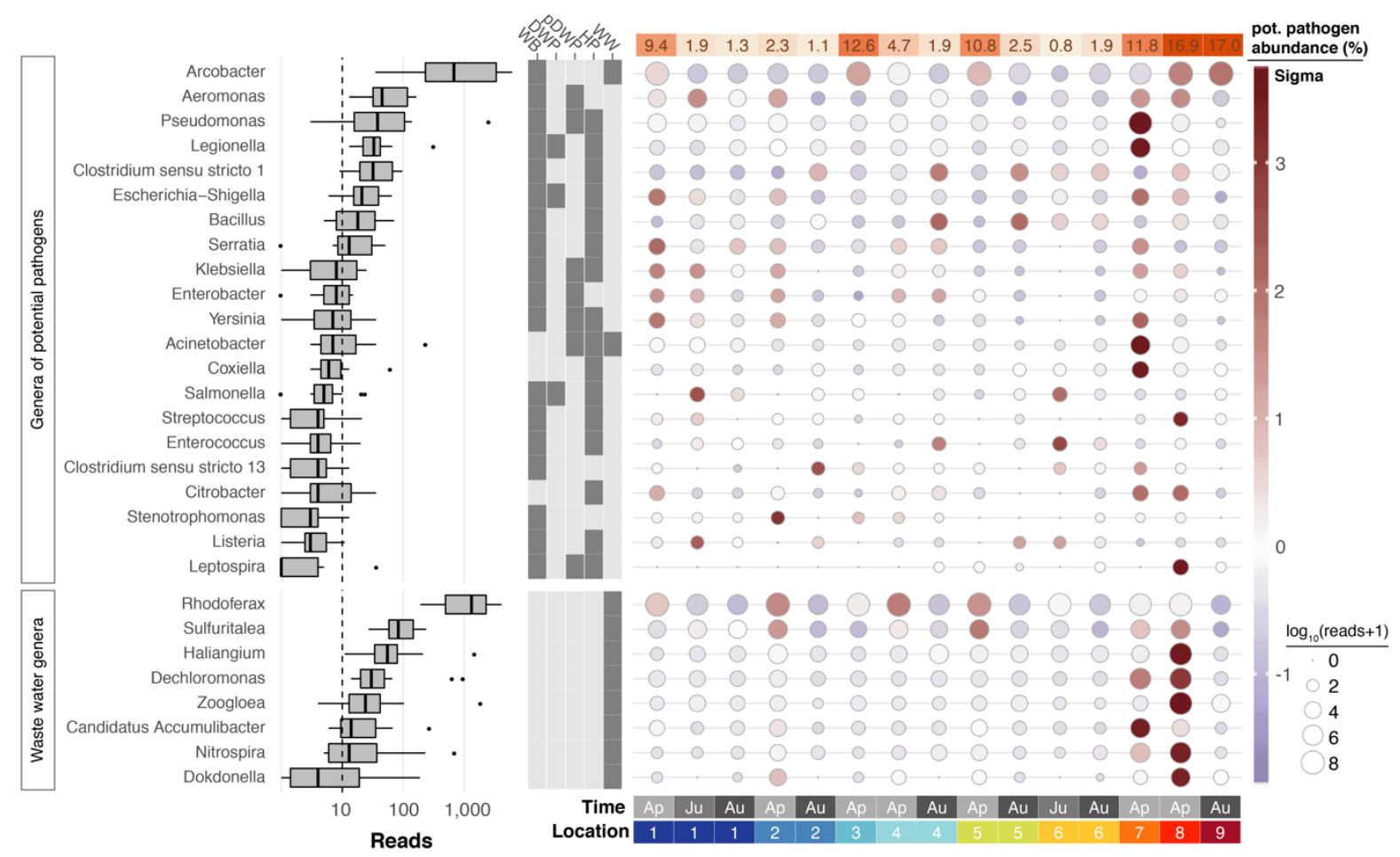

248 Figure 7: Potentially pathogenic and wastewater treatment related bacteria in the River Cam. Boxplots on the left show the abundance distribution across locations per bacterial genus. Error bars represent Q1 $-1.5 * \mathrm{IQR}$ (lower), and Q3 + 1.5*IQR (upper), respectively; Q1: first quartile, Q3: third quartile, IQR: interquartile range. The central table depicts the categorisation of subsets of genera as waterborne bacterial pathogens (WB), drinking water pathogens (DWP), potential drinking water pathogens (pDWP), human pathogens (HP) and core genera from wastewater treatment plants (WW) (dark grey: included, light grey: excluded) (Supplementary Table 3). The right-hand circle plot shows the distribution of bacterial genera across locations of the River Cam. Circle sizes represent overall read size fractions, while circle colours (sigma scheme) represent the standard deviation from the observed mean relative abundance within each genus.

Using multiple sequence alignments between nanopore reads and pathogenic species references, we further resolved the phylogenies of three common potentially pathogenic genera occurring in our river samples, Legionella, Salmonella and Pseudomonas (Figure 8a-c; Material and Methods). While Legionella and Salmonella diversities presented negligible levels of known harmful species, a cluster of reads in downstream sections indicated a low abundance of the opportunistic, environmental pathogen Pseudomonas aeruginosa (Figure 8c).

Along the course here investigated, we also found significant variations in relative abundances of the Leptospira genus, which was recently described to be enriched in wastewater effluents in Germany (Numberger et al., 2019) (Figure 8d). Indeed, the peak of River Cam Leptospira reads fell into an area of increased sewage influx ( $\sim .1 \%$ relative abundance; Figure 7). The Leptospira genus contains several potentially pathogenic species capable of causing life-threatening leptospirosis through waterborne infections, however also features close-related saprophytic and 'intermediate' taxa (Vincent et al., 2019; Wynwood et al., 2014). To resolve its complex 
bioRxiv preprint doi: https://doi.org/10.1101/2020 02.06 936302; this version posted November 18,2020 . The copyright holder for this preprint (which was not certified by peer review) is the author/funder, who has granted bioRxiv a license to display the preprint in perpetuity. It is made available under aCC-BY-NC-ND 4.0 International license.

phylogeny in the River Cam surface, we aligned Leptospira reads from all samples together with many reference

273 (Supplementary Figure 7) and correspondingly inflated read divergence, we could pinpoint spatial clusters and a

274 distinctly higher similarity between our amplicons and saprophytic rather than pathogenic Leptospira species.

275 These findings were subsequently validated by targeted, Leptospira species-specific qPCR (Supplementary Table

276 5; Material and Methods), confirming that R9.4.1 nanopore sequencing quality is already high enough to yield

277 indicative results for bacterial monitoring workflows at the species level.

278
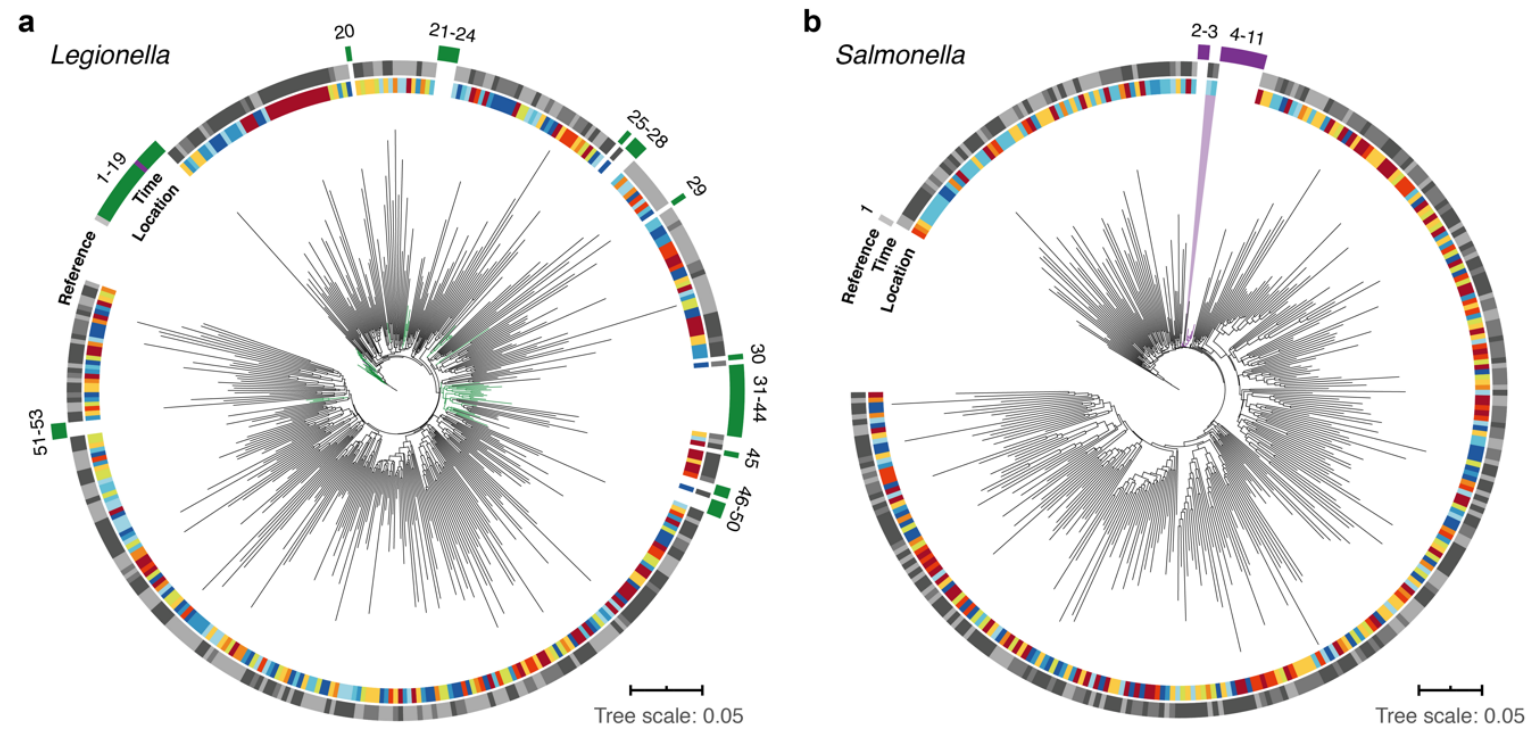

c

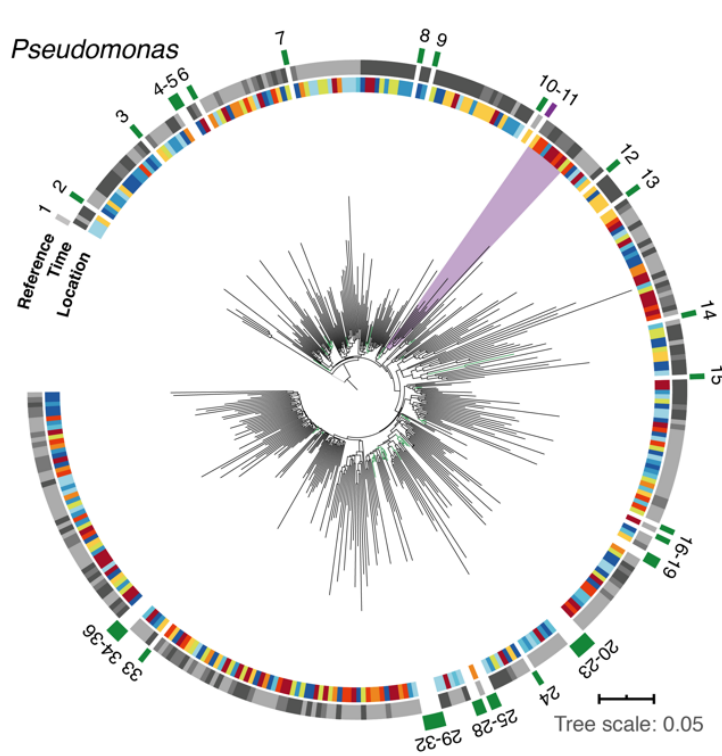

d
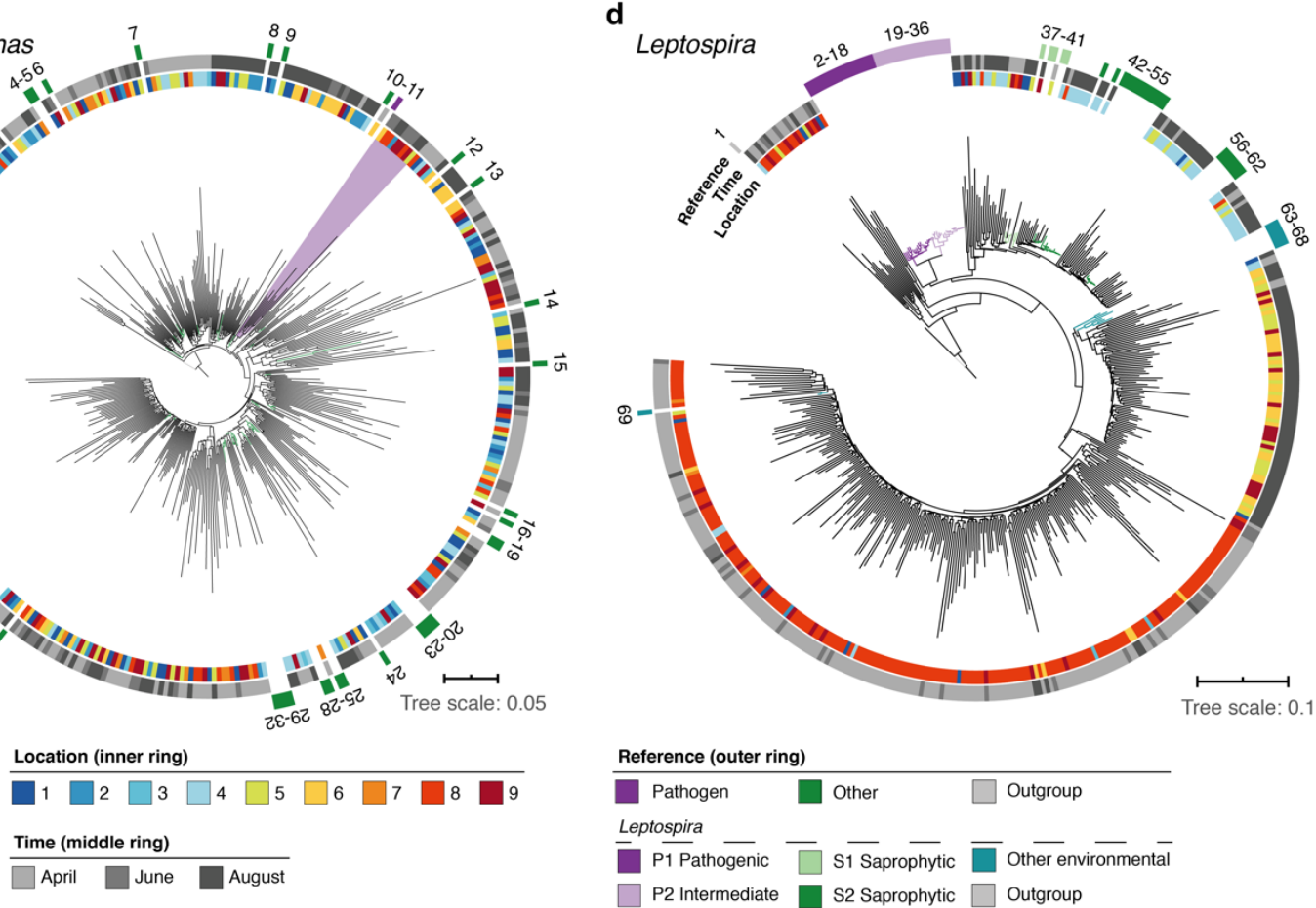
bioRxiv preprint doi: https://doi.org/10.1101/2020.02.06.936302; this version posted November 18, 2020. The copyright holder for this preprint (which was not certified by peer review) is the author/funder, who has granted bioRxiv a license to display the preprint in perpetuity. It is made available under aCC-BY-NC-ND 4.0 International license.

Figure 8: High-resolution phylogenetic clustering of candidate pathogenic genera in the River Cam. Phylogenetic trees illustrating multiple sequence alignments of exemplary River Cam nanopore reads (black branches) classified as (a) Legionella, (b) Salmonella, (c) Pseudomonas, or (d) Leptospira, together with known reference species sequences ranging from pathogenic to saprophytic taxa within the same genus (coloured branches). Reference species sequences are numbered in clockwise orientation around the tree (Supplementary Table 4). Nanopore reads highlighted in light violet background display close clustering with pathogenic isolates of (b) Salmonella spp. and (c) Pseudomonas aeruginosa.

\section{DISCUSSION}

Using a cost-effective, easily adaptable and scalable framework based on nanopore sequencing, we provide the first spatiotemporal nanopore sequencing atlas of bacterial microbiota throughout the course of a river. Our results suggest that this workflow allows for robust assessments of both, the core microbiome of an example fluvial ecosystem and heterogeneous bacterial compositions in the context of supporting physical (temperature, flow rate) and hydrochemical $(\mathrm{pH}$, inorganic solutes) parameters. We show that the technology's current sequencing accuracy of $\sim 92 \%$ allows for the designation of significant human pathogen community shifts along rural-tourban river transitions, as illustrated by downstream increases in the abundance of pathogen candidates.

Our assessment of bioinformatics workflows for taxonomic classification highlights current challenges with errorprone nanopore sequences. A number of recent reports feature bespoke $16 \mathrm{~S}$ read classification schemes centred around a single software (Acharya et al., 2019; Benitez-Paez, Portune, \& Sanz, 2016; Kerkhof, Dillon, Haggblom, \& McGuinness, 2017; Nygaard, Tunsjo, Meisal, \& Charnock, 2020), and others integrated outputs from two methods (Cusco, Catozzi, Vines, Sanchez, \& Francino, 2018). Through systematic benchmarking of twelve different classification tools, using matched mock community and river water datasets with respect to the SILVA v.132 reference database, we lay open key differences in terms of these methods' read (mis)classification rates, consensus agreements, speed and memory performance metrics. For example, our results indicate that very fast implementations like Kraken 2 or Centrifuge may yield less accurate classifications than slightly slower and more memory-demanding frameworks such as Minimap2 (Figure 2; Supplementary Figure 1).

Using Minimap2, 16.2\% of freshwater-derived sequencing reads were assigned to a bacterial species on average, thereby primarily encouraging automated analyses on the genus ( $65.6 \%$ assigned) or family level (76.6\% assigned). As nanopore sequencing quality continues to increase through refined pore chemistries, basecalling algorithms and consensus sequencing workflows (Calus, Ijaz, \& Pinto, 2018; Karst et al., 2020; Latorre-Perez, Villalba-Bermell, Pascual, \& Vilanova, 2020; Rang, Kloosterman, \& de Ridder, 2018; Santos, van Aerle, 
bioRxiv preprint doi: https://doi org/10.1101/2020.02 06.936302; this version posted November 18, 2020. The copyright holder for this preprint (which was not certified by peer review) is the author/funder, who has granted bioRxiv a license to display the preprint in perpetuity. It is made available under aCC-BY-NC-ND 4.0 International license.

313 Barrientos, \& Martinez-Urtaza, 2020), future bacterial taxonomic classifications are likely to improve and advance

314 opportunities for species discovery.

315

316 We show that nanopore amplicon sequencing data can resolve the core microbiome of a freshwater body, as well

317 as its temporal and spatial fluctuations. Common freshwater bacteria account for the vast majority of taxa in the

318 River Cam; this includes Sphingomonadaceae, which had also been previously found at high abundance in source

319 water from the same river (Rowe et al., 2016). Our findings suggest that the differential abundances of

320 Carnobacteriaceae most strongly contribute to seasonal loadings in the River Cam. Carnobacteriaceae have been

321 previously associated with a range of low temperature environments (Lawson \& Caldwell, 2014), and we found

322 these taxa to be more abundant in colder April samples (mean $11.3^{\circ} \mathrm{C}$, vs. $15.8^{\circ} \mathrm{C}$ in June and $19.1^{\circ} \mathrm{C}$ in August).

323 This might help to further establish this family as an indicator for bacterial community shifts along with

324 temperature fluctuations, albeit the influence of co-occurring hydrochemical trends such as $\mathrm{Ca}^{2+}$ and $\mathrm{Mg}^{2+}($ water

325 hardness), dissolved carbon or flow speed changes should also be noted (Figure 6b-d; Supplementary Figure 6).

327 Most routine freshwater surveillance frameworks focus on semi-quantitative diagnostics of only a limited number

328 of target taxa, such as pathogenic Salmonella, Legionella and faecal coliforms (Ramirez-Castillo et al., 2015; Tan

329 et al., 2015), whereas metagenomics approaches can give a complete and detailed overview of environmental

330 microbial diversity. Beyond nanopore shotgun-sequencing (Reddington et al., 2020), our proof-of-principle

331 analysis highlights that the combination of targeted full-length 16S rRNA gene MinION sequencing is a suitable

332 complement to hydrochemical controls in pinpointing relatively contaminated freshwater sites, some of which in

333 case of the River Cam had been previously highlighted for their pathogen diversity and abundance of antimicrobial

334 resistance genes (Rowe et al., 2017; Rowe et al., 2016). Nanopore amplicon sequencing has here allowed us to

335 reliably distinguish closely related pathogenic and non-pathogenic bacterial species of the common Legionella,

336 Salmonella, Pseudomonas and Leptospira genera. For Leptospira bacteria, which are of particular interest to

337 communal stakeholders of the River Cam, we validated nanopore sequencing results through the gold standard

338 qPCR workflow of Public Health England (Supplementary Table 5). In order to also study the potential viability

339 and functional implications of sequenced pathogen candidates for public health, we encourage future studies to

340 combine nanopore based freshwater metagenomics with targeted follow-up measurements of living pathogens by

341 established microbiological approaches, including species-specific isolation and subsequent culturing. 
bioRxiv preprint doi: https://doi.org/10.1101/2020.02 06.936302; this version posted November 18, 2020. The copyright holder for this preprint (which was not certified by peer review) is the author/funder, who has granted bioRxiv a license to display the preprint in perpetuity. It is made available under aCC-BY-NC-ND 4.0 International license.

343 A number of experimental intricacies should be addressed towards nanopore freshwater sequencing with our

344 approach, mostly by scrutinising water DNA extraction yields, PCR biases and molar imbalances in barcode

345 multiplexing (Figure 3a; Supplementary Figure 7). Similar to challenges with other organic substrates, microbial

346 raw DNA extraction protocols require careful pre-testing and optimisation towards the physicochemical

347 composition of a given freshwater source, in order to avoid both taxonomic enrichment biases and drop-offs in

348 total yield. One example lies in the optimisation of the filtrate volume - in this study, membrane DNA extraction

349 from $400 \mathrm{~mL}$ River Cam water was sufficient to yield valuable insights, while as much as $10,000 \mathrm{~mL}$ were used

350 in a previous study of the same river (Rowe et al., 2016). Moreover, potentially dissolved inhibitory compounds

351 for DNA extraction, sample cooling and storage chains should be thoroughly considered for larger and remote

352 river monitoring projects. We witnessed that yield variations may bear negative effects on the molar balance of

353 barcoded nanopore sequencing runs, as illustrated by elevated sample drop outs in June 2018, emphasising the

354 need for highly accurate concentration measurement and scaling when dozens of input DNA sources are pooled.

355 Our study further highlights that MinION (R9.4.1) flow cell throughput can fluctuate by an order of magnitude,

356 altogether causing the exclusion of measurements upon application of a conservative read threshold. We reason

357 that real-time selective nanopore sequencing could serve as a powerful means to improve barcode balances in

358 context of multiplexed 16S analyses (Loose, Malla, \& Stout, 2016), albeit such approaches are yet undergoing

359 computational optimisations (Kovaka, Fan, Ni, Timp, \& Schatz, 2020; Payne et al., 2020).

360

361 Our results show that it would already be theoretically feasible to obtain meaningful river microbiota from $>100$

362 barcoded samples on a single nanopore flow cell, thereby enabling water monitoring projects involving large

363 collections at costs below $£ 20$ per sample (Supplementary Table 6). In line with this, ONT has already released several commercial 96-barcode multiplexing kits for PCR and non-PCR based applications, as well as the smaller

365 'Flongle' flow cell with considerably reduced cost as compared to the traditional MinION model. On the other 366 hand, shotgun nanopore sequencing approaches may bypass pitfalls associated with amplicon sequencing, namely

367 taxon-specific primer biases (Frank et al., 2008), 16S rDNA copy number fluctuations between species (Darby,

368 Todd, \& Herman, 2013) or the omission of functionally relevant sequence elements. In combination with sampling

369 protocol adjustments, shotgun nanopore sequencing could moreover be used for the serial monitoring of eukaryotic microorganisms and viruses in freshwater ecosystems (Reddington et al., 2020). 
372 Since the commercial launch of the MinION in 2015, a wide set of microbial nanopore sequencing applications

373 in the context of rRNA gene (Benitez-Paez et al., 2016; Cusco et al., 2018; Kerkhof et al., 2017; Nygaard et al.,

374 2020) and shotgun (Leggett et al., 2019; Nicholls, Quick, Tang, \& Loman, 2019; Reddington et al., 2020; Stewart

375 et al., 2019) metagenomics have attracted the interest of a growing user community. Two independent case studies

376 have recently provided decomposition analyses of faecal bacterial pathogens in MinION libraries derived from

377 river and spring waters in Montana, USA (Hamner et al., 2019) and Kathmandu Valley, Nepal (Acharya et al.,

378 2019). Although it is to be expected that short-read metagenomics technology continues to provide valuable

379 environmental insights, as illustrated through global cataloguing efforts of ocean (Sunagawa et al., 2015) and

380 wastewater (Wu et al., 2019) microbiomes, due to their large sizes and fixed costs these traditional platforms

381 remain unfeasible for the monitoring of remote environments - especially in low-resource settings. We reason

382 that the convenience of MinION handling and complementary development of portable DNA purification methods

383 (Boykin et al., 2019; Gowers et al., 2019) will allow for such endeavours to become increasingly accessible to

384 citizens and public health organisations around the world, ultimately democratising the opportunities and benefits of DNA sequencing.

386 


\section{MATERIAL AND METHODS}

\section{$403 \quad 1.1$ Freshwater sampling}

404 We monitored nine distinct locations along a $11.62 \mathrm{~km}$ reach of the River Cam, featuring sites upstream, 405 downstream and within the urban belt of the city of Cambridge, UK. Measurements were taken at three time 406 points, in two-month intervals between April and August 2018 (Figure 1; Supplementary Table 1a). To warrant 407 river base flow conditions and minimise rain-derived biases, a minimum dry weather time span of $48 \mathrm{~h}$ was 408 maintained prior to sampling (Fisher, Newton, Dila, \& McLellan, 2015). One litre of surface water was collected 409 in autoclaved DURAN bottles (Thermo Fisher Scientific, Waltham, MA, USA), and cooled to $4{ }^{\circ} \mathrm{C}$ within three 410 hours. Two bottles of water were collected consecutively for each time point, serving as biological replicates of 411 location 9 (samples 9.1 and 9.2).

\section{$413 \quad 1.2$ Physical and chemical metadata}

414 We assessed various chemical, geological and physical properties of the River Cam (Figure 6; Supplementary 415 Figure 6; Supplementary Table 1b-c).

417 In situ water temperature was measured immediately after sampling. To this end, we linked a DS18B20 digital 418 temperature sensor to a portable custom-built, grid mounted Arduino nano v3.0 system. The $\mathrm{pH}$ was later recorded 419 under temperature-controlled laboratory conditions, using a pH edge electrode (HI-11311, Hanna Instruments, 420 Woodsocket, RI, USA).

422 To assess the dissolved ion concentrations in all collected water samples, we aerated the samples for 30 seconds 423 and filtered them individually through a $0.22 \mu \mathrm{M}$ pore-sized Millex-GP polyethersulfone syringe filter 424 (MilliporeSigma, Burlington, MA, USA). Samples were then acidified to $\mathrm{pH} \sim 2$, by adding $20 \mu \mathrm{L}$ of $7 \mathrm{M}$ distilled $425 \mathrm{HNO}_{3}$ per $3 \mathrm{~mL}$ sample. Inductively coupled plasma-optical emission spectroscopy (ICP-OES, Agilent 5100 426 SVDV; Agilent Technologies, Santa Clara, CA, USA) was used to analyse the dissolved cations $\mathrm{Na}^{+}, \mathrm{K}^{+}, \mathrm{Ca}^{2+}$, $427 \mathrm{Mg}^{2+}, \mathrm{Ba}^{2+}, \mathrm{Li}^{+}$, as well as $\mathrm{Si}$ and $\mathrm{SO}_{4}{ }^{2-}$ (as total $\mathrm{S}$ ) (Supplementary Table $1 \mathrm{~b}$ ). International water reference 428 materials (SLRS-5 and SPS-SW2) were interspersed with the samples, reproducing certified values within $10 \%$ 429 for all analysed elements. Chloride concentrations were separately measured on $1 \mathrm{~mL}$ of non-acidified aliquots of 430 the same samples, using a Dionex ICS-3000 ion chromatograph (Thermo Fisher Scientific, Waltham, MA, USA)

431 (Supplementary Table 1b). Long-term repeat measurements of a USGS natural river water standard T-143 
432 indicated precision of more than $4 \%$ for $\mathrm{Cl}^{-}$. However, the high $\mathrm{Cl}^{-}$concentrations of the samples in this study

433 were not fully bracketed by the calibration curve and we therefore assigned a more conservative uncertainty of 10

$434 \%$ to $\mathrm{Cl}^{-}$concentrations.

435

436 High calcium and magnesium concentrations were recorded across all samples, in line with hard groundwater and 437 natural weathering of the Cretaceous limestone bedrock underlying the river catchment (Figure 6a). There are no 438 known evaporite salt deposits in the river catchment, and therefore the high dissolved $\mathrm{Na}^{+}, \mathrm{K}^{+}$and $\mathrm{Cl}^{-}$ 439 concentrations in the River Cam are likely derived from anthropogenic inputs (Rose, 2007) (Figure 6c-d). We

440 calculated bicarbonate concentrations through a charge balance equation (concentrations in mol/L):

441 conc $\left(\mathrm{HCO}_{3}^{-}\right)=\operatorname{conc}\left(\mathrm{Li}^{+}\right)+\operatorname{conc}\left(\mathrm{Na}^{+}\right)+\operatorname{conc}\left(\mathrm{K}^{+}\right)+2 * \operatorname{conc}\left(\mathrm{Mg}^{2+}\right)+2 * \operatorname{conc}\left(\mathrm{Ca}^{2+}\right)-\operatorname{conc}\left(\mathrm{Cl}^{-}\right)-2^{*} \operatorname{conc}\left(\mathrm{S}^{2-}\right)$

443 The total dissolved solid (TDS) concentration across the 30 freshwater samples had a mean of $458 \mathrm{mg} / \mathrm{L}$ (range $444325-605 \mathrm{mg} / \mathrm{L}$ ) which is relatively high compared to most rivers, due to 1.) substantial solute load in the Chalk 445 groundwater (particularly $\mathrm{Ca}^{2+}, \mathrm{Mg}^{2+}$, and $\mathrm{HCO}_{3}{ }^{-}$) and 2.) likely anthropogenic contamination (particularly $\mathrm{Na}^{+}$, $446 \mathrm{Cl}^{-}$, and $\mathrm{SO}_{4}{ }^{2-}$ ). The TDS range and the major ion signature of the River Cam is similar to other anthropogenically 447 heavily-impacted rivers (Gaillardet et al., 1999), exhibiting enrichment in $\mathrm{Na}^{+}$(Figure 6d).

449 Overall, ion profiles clustered substantially between the three time points, indicating characteristic temporal shifts 450 in water chemistry. PC1 of a PCA on the solute concentrations $[\mu \mathrm{mol} / \mathrm{L}]$ shows a strong time effect, separating spring (April) from summer (June, August) samples (Figure 6b). We highlighted the ten most important features

452 (i.e., features with the largest weights) and their contributions to PC1 (Figure 6c).

454 We integrated sensor data sets on mean daily air temperature, sunshine hours and total rainfall from a public, 455 Cambridge-based weather station (Supplementary Figure 6a-c; Supplementary Table 1c). Similarly, mean gauged 456 daily Cam water discharge $\left[\mathrm{m}^{3} \mathrm{~s}^{-1}\right]$ of the River Cam was retrieved through publicly available records from three upstream gauging stations connected to the UK National River Flow Archive (https://nrfa.ceh.ac.uk/), together with historic measurements from 1968 onwards (Supplementary Figure 6d) 


\subsection{DNA extraction}

461 Within 24 hours of sampling, $400 \mathrm{~mL}$ of refrigerated freshwater from each site was filtered through an individual

$4620.22 \mu \mathrm{m}$ pore-sized nitrocellulose filter (MilliporeSigma, Burlington, MA, USA) placed on a Nalgene polysulfone

463 bottle top filtration holder (Thermo Fisher Scientific) at -30 mbar vacuum pressure. Additionally, $400 \mathrm{~mL}$ de-

464 ionised (DI) water was also filtered. We then performed DNA extractions with a modified DNeasy PowerWater

465 protocol (Qiagen, Hilden, Germany). Briefly, filters were cut into small slices with sterile scissors and transferred

466 to $2 \mathrm{~mL}$ Eppendorf tubes containing lysis beads. Homogenization buffer PW1 was added, and the tubes subjected

467 to ten minutes of vigorous shaking at $30 \mathrm{~Hz}$ in a TissueLyser II machine (Qiagen). After subsequent DNA binding

468 and washing steps in accordance with the manufacturer's protocol, elution was done in $50 \mu \mathrm{L}$ EB. We used Qubit

469 dsDNA HS Assay (Thermo Fisher Scientific) to determine water DNA isolate concentrations (Supplementary

470 Table 2a).

471

\section{$472 \quad 1.4$ Bacterial full-length 16S rDNA sequence amplification}

473 DNA extracts from each sampling batch and DI water control were separately amplified with V1-V9 full-length $474(\sim 1.45 \mathrm{kbp})$ 16S rRNA gene primers, and respectively multiplexed with an additional sample with a defined 475 bacterial mixture composition of eight species (Pseudomonas aeruginosa, Escherichia coli, Salmonella enterica,

476 Lactobacillus fermentum, Enterococcus faecalis, Staphylococcus aureus, Listeria monocytogenes, Bacillus 477 subtilis; D6305, Zymo Research, Irvine, CA, USA) (Figure 2), which was previously assessed using nanopore 478 shotgun metagenomics (Nicholls et al., 2019). We used common primer binding sequences $27 \mathrm{f}$ and $1492 \mathrm{r}$, both coupled to unique $24 \mathrm{bp}$ barcodes and a nanopore motor protein tether sequence (Supplementary Table 7). Full-

480 length $16 \mathrm{~S}$ rDNA PCRs were performed with $30.8 \mu \mathrm{L}$ DI water, $6.0 \mu \mathrm{L}$ barcoded primer pair $(10 \mu \mathrm{M}), 5.0 \mu \mathrm{L}$ 481 PCR-buffer with $\mathrm{MgCl}_{2}$ (10x), 5.0 $\mu \mathrm{L}$ dNTP mix (10x), $3.0 \mu \mathrm{L}$ freshwater DNA extract, and 0.2 $\mu \mathrm{L}$ Taq (Qiagen) 482 under the following conditions:

$48394{ }^{\circ} \mathrm{C}-2$ minutes

$48494{ }^{\circ} \mathrm{C}-30$ seconds, $60{ }^{\circ} \mathrm{C}-30$ seconds, $72{ }^{\circ} \mathrm{C}-45$ seconds $(35$ cycles $)$

$48572{ }^{\circ} \mathrm{C}-5$ minutes

486

\subsection{Nanopore library preparation}

488 Amplicons were purified from reaction mixes with a QIAquick purification kit (Qiagen). Two rounds of alcoholic washing and two additional minutes of drying at room temperature were then performed, prior to elution in $30 \mu \mathrm{L}$ 
491 barcoded extracts of a given batch were pooled in equimolar ratios, to approximately 300 ng DNA total

492 (Supplementary Table S2b). We used KAPA Pure Beads (KAPA Biosystems, Wilmington, MA, USA) to

493 concentrate full-length 16S rDNA products in $21 \mu \mathrm{L}$ DI water. Multiplexed nanopore ligation sequencing libraries

494 were then made by following the SQK-LSK109 protocol (Oxford Nanopore Technologies, Oxford, UK).

495

\subsection{Nanopore sequencing}

R9.4.1 MinION flow cells (Oxford Nanopore Technologies) were loaded with $75 \mu \mathrm{l}$ of ligation library. The MinION instrument was run for approximately 48 hours, until no further sequencing reads could be collected. Fast5 files were basecalled using Guppy (version 3.15) and output DNA sequence reads with Q>7 were saved as fastq files. Various output metrics per library and barcode are summarised in Supplementary Table 2c.

\subsection{Leptospira validation}

503 In collaboration with Public Health England, raw water DNA isolates of the River Cam from each location and

504 time point were subjected to the UK reference service for leptospiral testing (Supplementary Table 5). This test is based on quantitative real-time PCR (qPCR) of 16S rDNA and LipL32, implemented as a TaqMan assay for the detection and differentiation of pathogenic and non-pathogenic Leptospira spp. from human serum. Briefly, the assay consists of a two-component PCR; the first component is a duplex assay that targets the gene encoding the outer membrane lipoprotein LipL32, which is reported to be strongly associated with the pathogenic phenotype.

509 The second reaction is a triplex assay targeting a well conserved region within the 16S rRNA gene (rrn) in 510 Leptospira spp. Three different genomic variations correlate with pathogenic (PATH probe), intermediate (i.e.,

511 those with uncertain pathogenicity in humans; INTER probe) and non-pathogenic Leptospira spp. (ENVIRO 512 probe), respectively.

\section{2. DNA sequence processing workflow}

515 The described data processing and read classification steps were implemented using the Snakemake workflow 516 management system (Köster \& Rahmann, 2012) and are available on Github - together with all necessary 517 downstream analysis scripts to reproduce the results of this manuscript (https://github.com/d-j-k/puntseq). 
bioRxiv preprint doi: https://doi.org/10.1101/2020.02.06.936302; this version posted November 18, 2020. The copyright holder for this preprint (which was not certified by peer review) is the author/funder, who has granted bioRxiv a license to display the preprint in perpetuity. It is made available under aCC-BY-NC-ND 4.0 International license.

\section{$519 \quad 2.1$ Read data processing}

520 Reads were demultiplexed and adapters trimmed using Porechop (version 0.2.4,

521 https://github.com/rrwick/porechop). The only non-default parameter set was '--check_reads' (to 50,000), to 522 increase the subset of reads to search for adapter sets. Next, we removed all reads shorter than $1.4 \mathrm{kbp}$ and longer 523 than $1.6 \mathrm{kbp}$ with Nanofilt (version 2.5.0, https://github.com/wdecoster/nanofilt).

525 We assessed read statistics including quality scores and read lengths using NanoStat (version 1.1.2, 526 https://github.com/wdecoster/nanostat), and used Pistis (https://github.com/mbhall88/pistis) to create quality 527 control plots. This allowed us to assess GC content and Phred quality score distributions, which appeared 528 consistent across and within our reads. Overall, we obtained 2,080,266 reads for April, 737,164 for June, and $5295,491,510$ for August, with a mean read quality of 10.0 (Supplementary Table 2c).

\section{$531 \quad 2.2$ Benchmarking of bacterial taxonomic classifiers using nanopore reads}

532 We used twelve different computational tools for bacterial full-length 16S rDNA sequencing read classification

533 (section 2.2.1):

\begin{tabular}{|c|c|c|}
\hline Tool & Version & Commands \\
\hline $\begin{array}{l}\text { BLASTN (Altschul, } \\
\text { Gish, Miller, Myers, } \\
\text { \& Lipman, 1990; } \\
\text { Camacho et al., 2009) }\end{array}$ & v.2.9.0+ & $\begin{array}{l}\text { blastn -task "blastn" -db silva.fa -query Cam16S.fa -out } \\
\text { Cam16S.out -outfmt '6' }\end{array}$ \\
\hline $\begin{array}{l}\text { Centrifuge (Kim et } \\
\text { al., 2016) }\end{array}$ & v.1.0.4 & $\begin{array}{l}\text { centrifuge -x centrifuge_silva -U Cam16S.fq -S Cam16S.out -- } \\
\text { report-file Cam16S.report }\end{array}$ \\
\hline $\begin{array}{l}\text { IDTAXA (Murali et } \\
\text { al., 2018) }\end{array}$ & $\begin{array}{l}\text { Implemented in } \mathrm{R} \\
\text { DECIPHER } \\
\text { v.2.10.2 (Wright, } \\
\text { 2016) }\end{array}$ & $\begin{array}{l}\text { load(“SILVA_SSU_r132_March2018.RData") } \\
\text { IdTaxa(Cam16S.fa, trainingSet, strand = "both", threshold =0) }\end{array}$ \\
\hline $\begin{array}{l}\text { Kraken } 2 \text { (Wood, Lu, } \\
\text { \& Langmead, 2019; } \\
\text { Wood \& Salzberg, } \\
\text { 2014) }\end{array}$ & v.2.0.7 & $\begin{array}{l}\text { kraken2 --db kraken2_silva --output Cam16S.out --report } \\
\text { Cam16S.report Cam16S.fa }\end{array}$ \\
\hline $\begin{array}{l}\text { MAPseq (Matias } \\
\text { Rodrigues et al., } \\
\text { 2017) }\end{array}$ & v.1.2.3 & mapseq Cam16S.fa silva.fa $>$ Cam16S.out \\
\hline $\begin{array}{l}\text { MegaBLAST } \\
\text { (Camacho et al., } \\
\text { 2009; Morgulis et al., } \\
\text { 2008) }\end{array}$ & v.2.9.0+ & $\begin{array}{l}\text { blastn -task "megablast" -db silva.fa -query Cam16S.fa -out } \\
\text { Cam16S.out -outfmt '6' }\end{array}$ \\
\hline
\end{tabular}


bioRxiv preprint doi: https://doi.org/10.1101/2020.02 06.936302; this version posted November 18, 2020. The copyright holder for this preprint (which was not certified by peer review) is the author/funder, who has granted bioRxiv a license to display the preprint in perpetuity. It is made available under aCC-BY-NC-ND 4.0 International license.

\begin{tabular}{|l|l|l|}
\hline Minimap2 (Li, 2018) & v.2.13-r852-dirty & $\begin{array}{l}\text { minimap2 -ax map-ont -L silva.mmi Cam16S.fa }> \\
\text { Cam16S.sam }\end{array}$ \\
\hline $\begin{array}{l}\text { Mothur (Schloss et } \\
\text { al., 2009) }\end{array}$ & v.1.43.0 & $\begin{array}{l}\text { align.seqs(candidate=Cam16S.fa, } \\
\text { template=mothur.silva.nr_v132.align, processors=1, ksize=6, } \\
\text { align=needleman) }\end{array}$ \\
\hline $\begin{array}{l}\text { QIIME 2 (Bolyen et } \\
\text { al., 2019) }\end{array}$ & v.2019.7 & $\begin{array}{l}\text { qiime feature-classifier classify-consensus-blast --i-query } \\
\text { Cam16S.qza --i-reference-reads silva.qza --i-reference- } \\
\text { taxonomy silva_tax.qza --o-classification Cam16S.out }\end{array}$ \\
\hline $\begin{array}{l}\text { RDP (Wang et al., } \\
\text { 2007) }\end{array}$ & $\begin{array}{l}\text { Implemented in R } \\
\text { DADA2 v.1.12.1 } \\
\text { Callahan et al., } \\
\text { 2016) }\end{array}$ & $\begin{array}{l}\text { assignTaxonomy(seqs = Cam16S.fa, refFasta }= \\
\text { silva_nr_v132_train_set.fa.gz", tryRC }=\text { T, } \\
\text { outputBootstraps=T,minBoot=0) }\end{array}$ \\
\hline $\begin{array}{l}\text { SINTAX (R.C. } \\
\text { Edgar, 2016) }\end{array}$ & $\begin{array}{l}\text { Implemented in } \\
\text { VSEARCH } \\
\text { v.2.13.3 (Rognes, } \\
\text { Flouri, Nichols, } \\
\text { Quince, \& Mahe, } \\
\text { 2016) }\end{array}$ & $\begin{array}{l}\text { vsearch -sintax Cam16S.fa -db silva.udb } \\
\text {-tabbedout Cam16S.out -strand both -sintax_cutoff 0.5 }\end{array}$ \\
\hline $\begin{array}{l}\text { SPINGO (Allard et } \\
\text { al., 2015) }\end{array}$ & $\begin{array}{l}\text { v.1.3 } \\
\text { spingo -d silva.fa -k 8 -a -i Cam16S.fa }>\text { Cam16S.out }\end{array}$ \\
\hline
\end{tabular}

\section{$535 \quad$ 2.2.1 Datasets}

536 We used nanopore sequencing data from our mock community and freshwater amplicons for benchmarking the

537 classification tools. We therefore subsampled (a) 10,000 reads from each of the three mock community sequencing 538 replicates (section 1.4), and (b) 10,000 reads from an aquatic sample (April-8; three random draws served as 539 replicates). We then used the above twelve classification tools to classify these reads against the same database, 540 SILVA v.132 (Quast et al., 2013) (Figure 2; Supplementary Figure 1).

\section{$542 \quad$ 2.2.2 Comparison of mock community classifications}

543 For the mock community classification benchmark, we assessed the number of unclassified reads, misclassified 544 reads (i.e. sequences not assigned to any of the seven bacterial families), and the root mean squared error (RMSE) 545 between observed and expected taxon abundance of the seven bacterial families. Following the detection of a 546 strong bias towards the Enterobacteriaceae family across all classification tools, we also analysed RMSE values 547 after exclusion of this family (Figure $2 b-c)$. 


\subsubsection{Comparison of river community classifications}

550 For the aquatic sample, the number of unclassified reads were counted prior to monitoring the performance of each classification tool in comparison with a consensus classification, which we defined as majority vote across classifications from all computational workflows. We observed stable results across all three draws of 10,000 reads from the same dataset (data not shown), indicating a robust representation of the performance of each classifier.

\subsubsection{Memory and runtime measurements}

557 To systematically assess the computational requirements and performance metrics of the twelve classification methods, 15 random subsamples of the same aquatic sample (April-8) were drawn. This test set involved $5 \times 100$, $5 \times 1,000$ and $5 \times 10,000$ reads, each of which were independently classified by the different software frameworks (commands summarised in section 2.2). CPU time, average and peak memory metrics were recorded on a single computing node (Supplementary Figure 1). Due to their reusability, tool-specific reference index file generations were omitted from these measurements.

\subsubsection{Overall classification benchmark}

565 Minimap2 performed second best at classifying the mock community (lowest RMSE), while also delivering freshwater bacterial profiles in line with the majority vote of other classification tools (Figure 2), in addition to providing comparably rapid speed (Supplementary Figure 1). To classify each of this study's full MinION data sets within a reasonable memory limit of $50 \mathrm{~Gb}$, it was necessary to reduce the number of threads to 1 , set the kmer size ('-k') to 15 and the minibatch size ('-K') to $25 \mathrm{M}$.

\subsection{Bacterial analyses}

\subsubsection{General workflow}

574 After applying Minimap2 to the processed reads as explained above (section 2.2.5), we processed the resulting

575 SAM files by firstly excluding all header rows starting with the '@' sign and then transforming the sets of read IDs, SILVA IDs, and alignment scores to tsv files of unique read-bacteria assignments either on the bacterial genus or family level. All reads that could not be assigned to the genus or family level were discarded, respectively. 
taxonomic level in which these multiple taxa would be included. If this level was above the genus or family level, respectively, we discarded the read.

581

\subsubsection{Estimating the level of misclassifications and DNA contaminants}

583 Across three independent sequencing replicates of the same linear bacterial community standard (section 2.2.1), we found that the fraction of reads assigned to unexpected genus level taxa lies at $\sim 1 \%$ when using the Minimap2 classifier and the SILVA v.132 database.

586

Raw quantified DNA, PCR amplicons and sequencing read counts were considerably less abundant in DI water negative controls, as compared to actual freshwater specimens (Supplementary Table 2a). Only the negative control of the most prolific flow cell run (August 2018) passed the relatively high confidence threshold of 37,000 sequencing reads on the family level (Figure 3b; Supplementary Figure 3; section 2.4). Further inspection of these negative control reads revealed that their metagenomic profile closely mimicked the taxonomic classification profiles of river samples within the same sequencing batch, in addition to low-level kit contaminants like alphaproteobacteria of the Bradyrhizobium and Methylobacterium genus (Salter et al., 2014) which were otherwise nearly completely absent in any of the true aquatic isolates (Supplementary Table 8).

\subsubsection{Determination of nanopore sequencing accuracy}

597 Minimap2 alignments against mock community taxa were used to determine the mean read-wise nanopore sequencing accuracy for this study ( $92.08 \%)$, as determined by the formula: accuracy $=1-($ read mismatch length $\div$ read alignment length $)$

These values were calculated for each of all eight species against each sequencing replicate, using the samtools

\subsection{Rarefaction and high-confidence samples}

605 Sample-specific rarefaction curves were generated by successive subsampling of sequencing reads classified by

606 Minimap2 against the SILVA v.132 database (section 2.2.1). For broader comparative data investigations, we 607 chose to only retain samples that passed a conservative minimum threshold of 37,000 reads. Family and genus 608 level species richness was hence kept at $\sim 90 \%$ of the original values, in accordance with stable evenness profiles 
across a series of 100 bootstrap replicates (Supplementary Figure 3; section 2.4.1). Although we mainly present a

610 single example rarefied dataset within this manuscript, we repeated each analysis, including PCAs, hierarchical

611 clustering and Mantel tests, based on additional rarefied datasets to assess the stability of all results.

612

\section{$613 \quad$ 2.4.1 Mantel test}

614 We performed Mantel tests to compare rarefied datasets with the full dataset. We therefore compared the

615 Euclidean distance based on Z-standardised bacterial genera between all samples with more than 37,000 reads

616 (two-sided test, 99,999 permutations). This resulted in a Pearson correlation of $0.814\left(\mathrm{p}=2.1 * 10^{-4}\right)$ for our main

617 rarefied dataset (results of the Mantel test applied to the remaining three other rarefied datasets: $R=0.819$ and $p$

$618=1.0 * 10^{-4}, \mathrm{R}=0.828$ and $\mathrm{p}=8.0^{*} 10^{-5}, \mathrm{R}=0.815$ and $\mathrm{p}=1.4^{*} 10^{-4}$, respectively). Results of the Mantel tests

619 applied to the genus level bacterial classifications were also similar for all four subsampled datasets $(\mathrm{R}=0.847$ and $\mathrm{p}=1.0^{*} 10^{-5}, \mathrm{R}=0.863$ and $\mathrm{p}=1.0^{*} 10^{-5}, \mathrm{R}=0.851$ and $\mathrm{p}=1 * 10^{-5}, \mathrm{R}=0.856$ and $\left.\mathrm{p}=1.0^{*} 10^{-5}\right)$.

621

\subsection{Meta-level bacterial community analyses}

623 All classification assessment steps and summary statistics were performed in R or Python (https://github.com/d-

$624 \mathrm{j}-\mathrm{k} /$ puntseq). We used the Python package scikit-bio for the calculation of the Simpson index and the Shannon's 625 diversity as well as equitability index.

\subsection{Hierarchical clustering, principal component, mixture model and outlier analyses}

628 Rarefied read count data was subjected to a $\log _{10}(x+1)$ transformation before hierarchical clustering using the 629 complete linkage method. Resulting family and genus dendrograms were separated into four groups (clusters C1

$630-\mathrm{C} 4$ ), while sample trees were split into two groups (separating mock communities from aquatic samples).

632 For PCA analyses, rarefied read count data was subjected to $\log 10(\mathrm{x}+1)$ and Z-transformations. Negative control 633 samples were removed. Mock community samples were initially removed to then be re-aligned to the eigenspace 634 determined by the aquatic samples. We provide PCA visualisations of the four main principal components (PCs 635 explaining $>5 \%$ variance, respectively). For each of these relevant PCs, we further highlight the ten most 636 important features (i.e. taxa with largest weights) and their contributions to the PCs in barplots. To assess statistical 637 differences in the PC3 component contribution between the three seasonal time points, a Kruskal-Wallis H-test 
with corresponding aquatic sample groupings was applied, followed by post-hoc comparisons using two-sided

Mann-Whitney U rank tests.

640

641 We fit a zero-inflated log-normal mixture model of each bacterial taxon against the different time points using the

642 fitFeatureModel function embedded in the R package metagenomeSeq (Paulson, Stine, Bravo, \& Pop, 2013). As

643 only three independent variables can be accounted for by the model (including the intercept), we chose to

644 investigate the difference between the spring (April) and summer (June, August) months. Seven significant

645 bacterial taxa were inspected below a nominal P-value threshold of 0.05: Cyanobiaceae $\left(1.5^{*} 10^{-5}\right)$, Listeriaceae

$646\left(2.0^{*} 10^{-4}\right), \quad$ Azospirillaceae $\left(6.8^{*} 10^{-4}\right), \quad$ Cryomorphaceae $\left(1.3^{*} 10^{-3}\right), \quad$ Carnobacteriaceae $\quad\left(4.3^{*} 10^{-3}\right)$,

647 Microbacteriaceae (0.014), Armatimonadaceae (0.046).

648

649 To determine location and time point-specific bacterial overabundance (outlier analysis), we identified taxa which

650 were 1.) tagged by more than 500 reads and 2.) at least five times more abundant in any single sample than in the mean of all samples combined.

652

\section{$653 \quad 2.7$ Identification of the core microbiome}

654 The core microbiome was calculated based on rarefied read count data from four independent downsampling sets on either family or genus level (Figure 4; Supplementary Figure 4). It represents the most abundant taxa that

656 showed relatively consistent abundance profiles between samples, based on hierarchical clustering analysis on one independent rarefaction (Figure 4a, C2 and C4; Supplementary Figure 4a, C3 and C2) and rarefactions with a median abundance of $>0.1 \%$. For the genus level, only those with median abundance of $>0.2 \%$ are displayed.

659

\section{$660 \quad 2.8$ Pathogen candidate assessments}

661 A list of 55 known bacterial pathogenic genera, spanning 37 families, was compiled for targeted sequence testing.

662 This was done through the manual integration of curated databases and online sources, foremost using PATRIC

663 (Wattam et al., 2017) and data on known waterborne pathogens (Jin et al., 2018) (Supplementary Table 3a).

664 Additionally, we integrated known genera from a large wastewater reference collection (Wu et al., 2019)

665 (Supplementary Table 3b). 
667 To identify if DNA reads assigned to Leptospiraceae were more similar to sequence reads of previously identified

668 pathogenic, intermediate or environmental Leptospira species, we built a neighbour-joining tree of Leptospiraceae

669 reads classified in our samples data, together with sequences from reference databases (Figure 8d; species names

670 and NCBI accession numbers in clockwise rotation around the tree in Supplementary Table 4d). We matched the

671 orientation of our reads, and then aligned them with 68 Leptospira reference sequences and the Leptonema illini

672 reference sequence (DSM 21528 strain 3055) as an outgroup. We then built a neighbour-joining tree using Muscle

673 v.3.8.31 (R. C. Edgar, 2004), excluding three reads in the 'Other Environmental' clade that had extreme branch

674 lengths $>0.2$. The reference sequences were annotated as pathogenic and saprophytic clades P1, P2, S1, S2 as

675 recently described (Vincent et al., 2019). Additional published river water Leptospira that did not fall within these

676 clades were included as 'Other Environmental' (Ganoza et al., 2006). Similarly, we constructed phylogenies for

677 the Legionella, Salmonella and Pseudomonas genus, using established full-length 16S reference species sequences

678 from NCBI (Figure 8a-c; Supplementary Table 4a-c).

679

\section{3. Total project cost}

681 This study was designed to enable freshwater microbiome monitoring in budget-constrained research environments. Although we had access to basic infrastructure such as pipettes, a PCR and TissueLyser II machine, as well a high-performance laptop, we wish to highlight that the total sequencing consumable costs were held below $£ 4,000$ (Supplementary Table $6 a$ ). Individual processing and sequencing costs ranged at $\sim £ 75$ per sample

685 (Supplementary Table 6b). With the current MinION flow cell price of $£ 720$, we estimate that per-sample costs could be further reduced to as low as $\sim £ 20$ when barcoding and pooling $\sim 100$ samples in the same sequencing run

687 (Supplementary Table 6c). Assuming near-equimolar amplicon pooling, flow cells with an output of $\sim 5,000,000$ reads can yield well over 37,000 sequences per sample and thereby surpass this conservative threshold applied here for comparative river microbiota analyses. 
697 We wish to thank reviewers Dr. María Mercedes Zambrano, Dr. Alejandro Sanchez-Flores, and reviewing editor

698 Dr. Bavesh Kana for their valuable comments and improvements to this manuscript, particularly during the 699 worldwide pandemic of COVID-19. We further thank Meltem Gürel, Christian Schwall, Jack Monahan, Eirini

700 Vamva, Astrid Wendler, Ben Wagstaff, Elliot Brooks, Jennifer Pratscher, Rob Field, David Seilly, Mervyn

701 Greaves, Tim Brooks, Daniel Bailey, Jenny Molloy, Michal Filus, Aleix Lafita, Oana Stroe, Abigail Wood, Paul

702 Saary, Jane Clarke, Fiona Gilsenan and her family, Nick Loman, Zamin Iqbal, Rob Finn, Alex Greenwood,

703 Daniela Numberger, Julian Parkhill, Simon Frost, Sam Stubbs, Mark Holmes, Alicja Dabrowska, Alex Patto,

704 Adrien Leger, Kim Judge, Alina Ham, Dan Fordham, Heather Martinez, Gemma Gambrill, Víctor de Lorenzo,

705 David Sargan, Lisa Schmunk, Amanda Clare, Alejandro de Miquel Bleier and Alison Smith for helpful comments and assistance with this project. We thank Lilo and Manfred Fuchs from the Fuchs Fund for supporting LU's conference participation and presentation.

FUNDING

710 This study was funded by the OpenPlant Fund (BBSRC BB/L014130/1) and the University of Cambridge RCUK

711 Catalyst Seed Fund. LU, MH and DEMH were funded by an EMBL PhD Fellowship. LU's Fellowship was

712 financed by the European Union's Horizon2020 research and innovation programme (grant agreement number 713 N635290). AH and MRS received Gates Cambridge Trust PhD scholarships. DJK was supported by the Wellcome

714 Trust under grants 203828/Z/16/A and 203828/Z/16/Z. MJS was funded through the Oliver Gatty Studentship.

715 SNP was funded by Wellcome Ph.D. Studentship 102453/Z/13/Z. JJB and ETT acknowledge NERC standard grant NE/P011659/1.

\section{AUTHOR CONTRIBUTIONS}

719 LU, AH, JJB, PBW, MJS, DJK, ETT and MRS designed the research; PBW, DJK, DEMH and MRS acquired 720 project funding; LU, AH, PBW, MJS, SNP, DJK, DEMH and MRS collected river samples; LU, AH, JJB, PBW, MJS, SNP, DJK and MRS performed the experiments; LU, AH, JJB, MH, SJS, and MRS analysed the data; LU,

722 AH and MRS wrote the paper with input from all co-authors.

\section{COMPETING INTERESTS}

All authors of this manuscript declare no competing interest. 
MATERIALS AND CORRESPONDENCE

728 Correspondence and requests for materials should be addressed to Maximilian Stammnitz 729 (maxrupsta@gmail.com), or to Andre Holzer (andre.holzer.biotech@gmail.com) and Lara Urban 730 (lara.h.urban@gmail.com).

\section{DATA AVAILABILITY}

733 Sequencing datasets generated and analysed during this study are available from the European Nucleotide

734 Archive, project accession PRJEB34900 (https://www.ebi.ac.uk/ena/data/view/PRJEB34900). The following 735 figures of this manuscript are based on this data: Figures 2, 3, 4, 5, 7, 8, Supplementary Figures 1, 3, 4, 5, 7. 736 Environmental measurements are available from public repositories, 737 https://www.cl.cam.ac.uk/research/dtg/weather/ and https://nrfa.ceh.ac.uk/. The following figures of this 738 manuscript are based on this data: Figure 6 and Supplementary Figure 6. There are no restrictions on data availability.

\section{CODE AVAILABILITY}

742 Our Github repository (https://github.com/d-j-k/puntseq/) features a Snakemake framework that integrates all data

743 pre-processing steps, and a Singularity that contains all necessary software (https://github.com/d-j-

$744 \mathrm{k} /$ puntseq/tree/master/analysis/). We further provide complete and rarefied SILVA 132 classifications from runs 745 of Minimap2 (https://github.com/d-j-k/puntseq/tree/master/minimap2_classifications), which can be directly used as an input for reproducible downstream analyses. 
bioRxiv preprint doi: https://doi org/10.1101/2020.02 06.936302; this version posted November 18, 2020. The copyright holder for this preprint (which was not certified by peer review) is the author/funder, who has granted bioRxiv a license to display the preprint in perpetuity. It is made available under aCC-BY-NC-ND 4.0 International license.

\section{SUPPLEMENTARY FIGURES}

a Most abundant families

\begin{tabular}{llll}
\hline Burkholderiaceae & Spirosomaceae & Haliangiaceae & Sphingomonadaceae \\
Arcobacteraceae & NS11-12 marine group & Saprospiraceae & Other families \\
Rhodocyclaceae & Dikarya & Rhodobacteraceae & \\
\hline
\end{tabular}

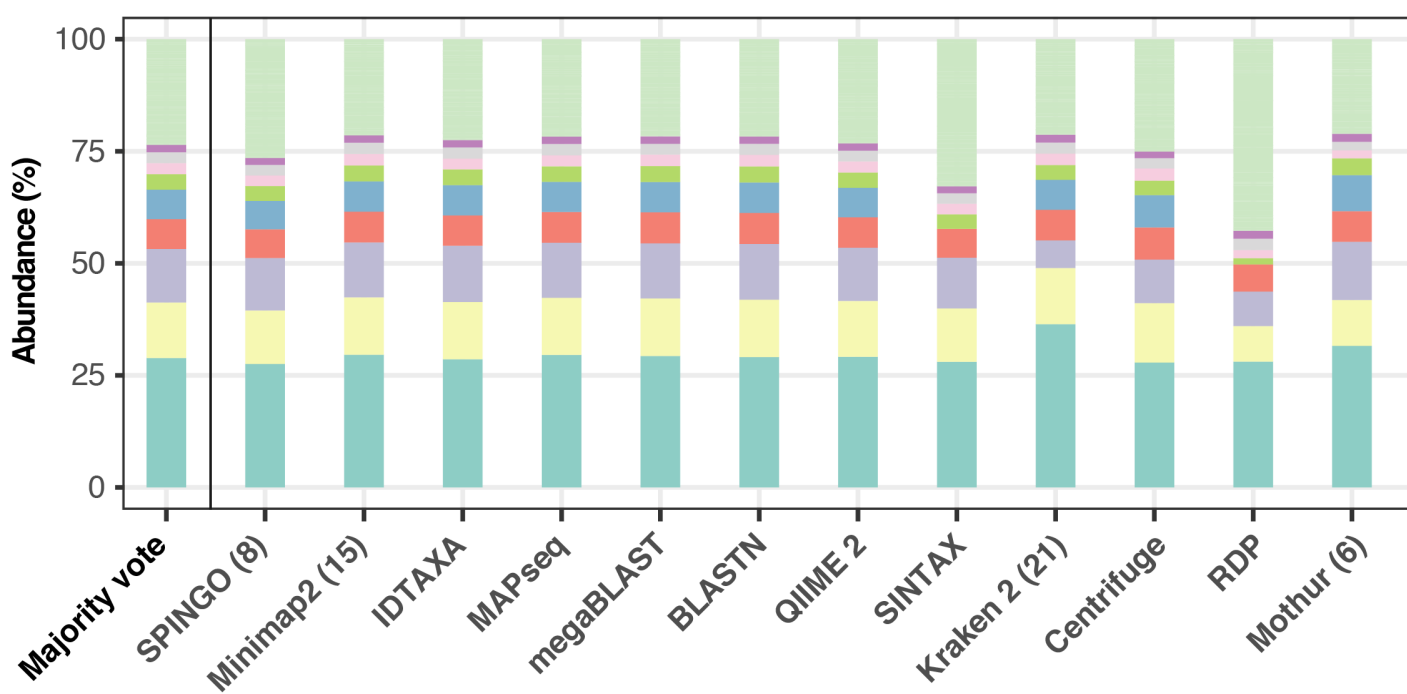

b

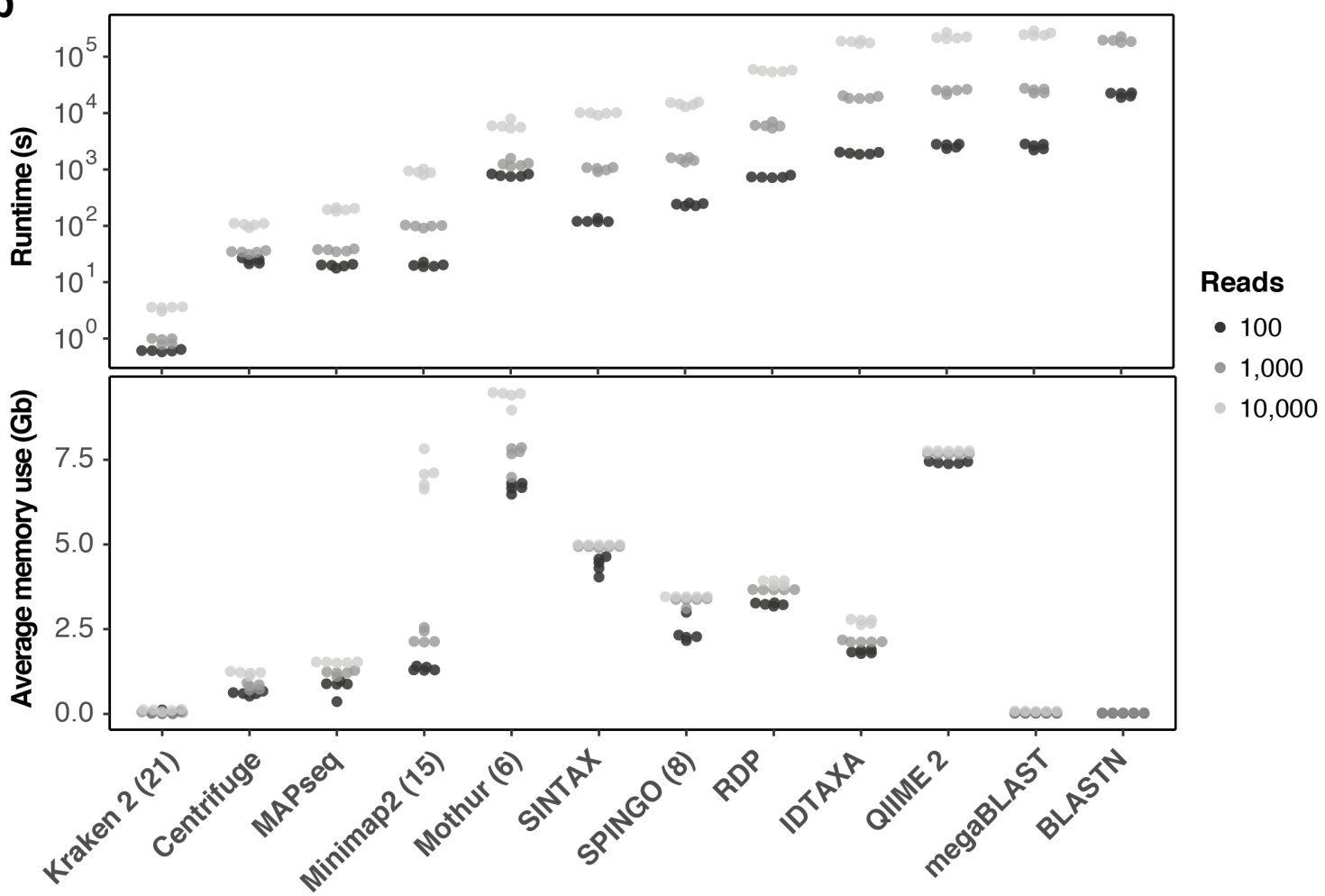

Supplementary Figure 1: Benchmarking of twelve taxonomic classifiers with nanopore full-length 16S

sequences. (a) Top 10 represented bacterial taxon families across all methods, based on the 10,000 aquatic reads used in Figure 2d. (b) Comparison of computational performances with respect to (upper) runtime and average memory (lower) usage for the classification of $5 \times 100,5 \times 1,000$ and $5 \times 10,000$ random read draws of the same sample. BLASTN based classifications of 10,000 read sets are omitted, as their runtimes exceeded 14 days $\left(>10^{6}\right.$ seconds). 


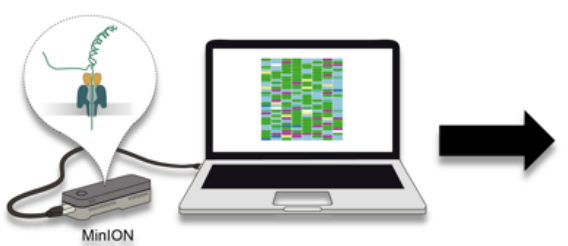

DNA Sequencing

R9.4.1 flow cell with LSK109

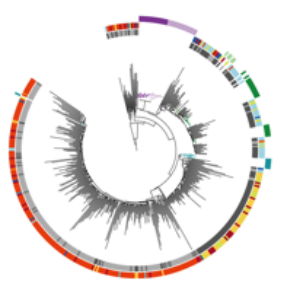

Metagenomic analyses

phylogenetics, spatiotemporal clustering, hydrochemical associations

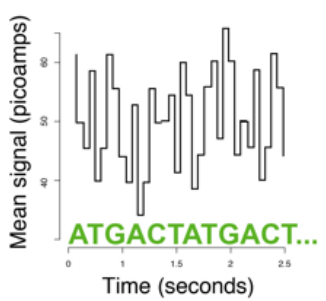

Basecalling

Guppy 3.15 (FlipFlop)
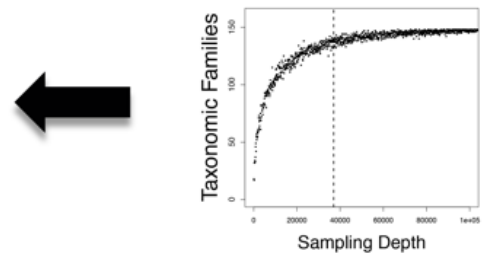

Rarefaction

to 37,000 reads

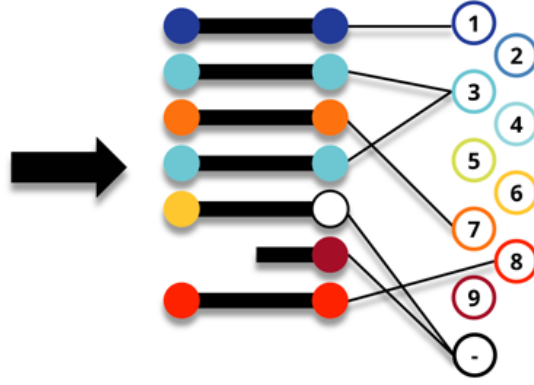

Barcode assignment Porechop 0.2.4
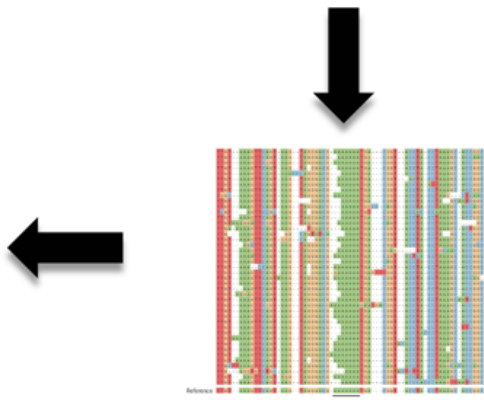

Taxonomic classification

Minimap2 $(k=15)$ vs. SILVA 132

Supplementary Figure 2: Bioinformatics consensus workflow. Essential data processing steps, from nanopore sequencing to spatiotemporal bacterial composition analysis (Material and Methods). After full-length 16S rDNA sequencing with the MinION (R9.4.1 flow cell), local basecalling of the raw fast5 files was performed using Guppy (Wick, Judd, \& Holt, 2019). Output fastq files were filtered for length and quality (Material and Methods), and reads assigned to their location barcode using Porechop. We then used Minimap2 $(\mathrm{k}=15)$ and the SILVA v.132 database for taxonomic classifications. Rarefaction reduced each sample to the same number of reads $(37,000)$, allowing for a robust comparison of bacterial composition across samples in various analyses. 
bioRxiv preprint doi: https://doi.org/10.1101/2020.02 06 936302; this version posted November 18,2020 . The copyright holder for this preprint (which was not certified by peer review) is the author/funder, who has granted bioRxiv a license to display the preprint in perpetuity. It is made available under aCC-BY-NC-ND 4.0 International license.
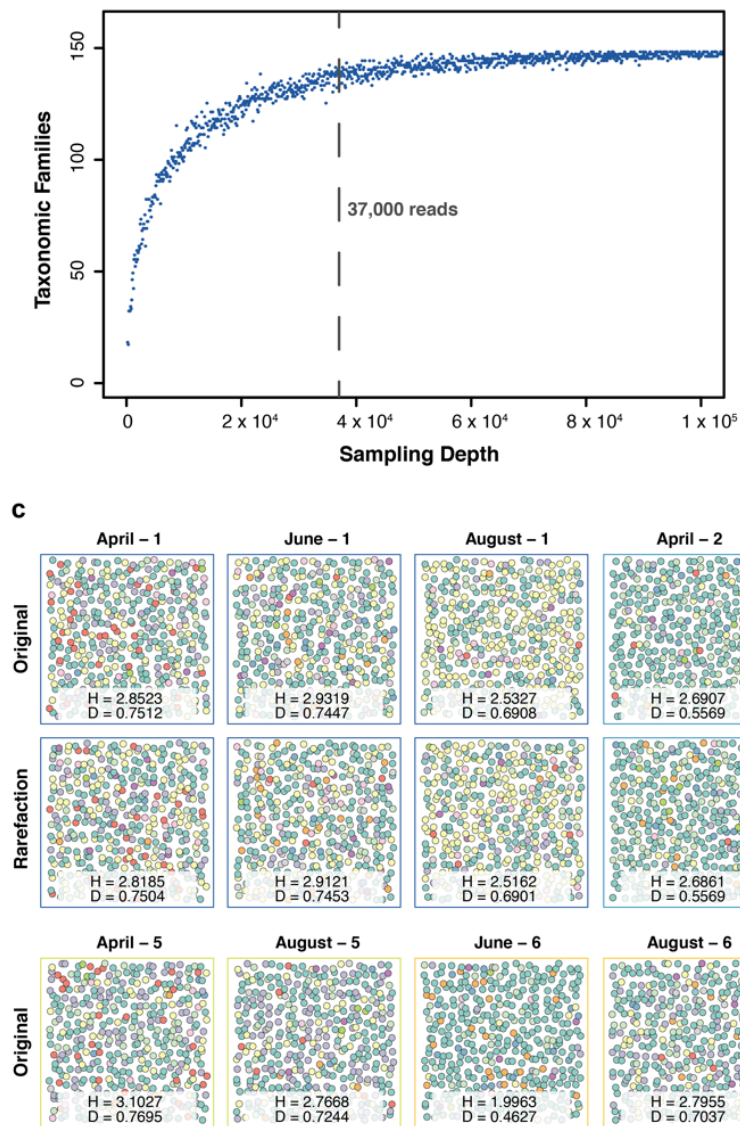

August - 5
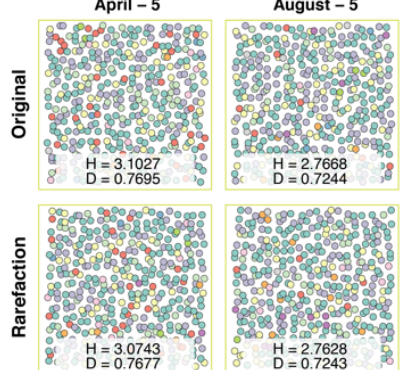

undant families

Burkholderiaceae
Spirosomaceae
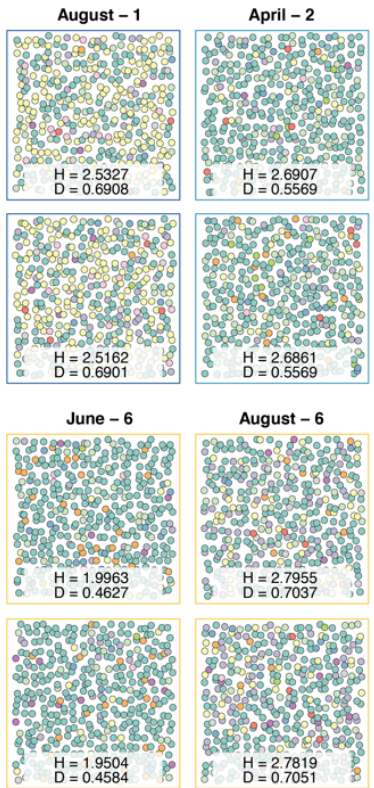

Sphingomonadacea
Rhodobacteraceae between pairs of original and rarefied sets.

b
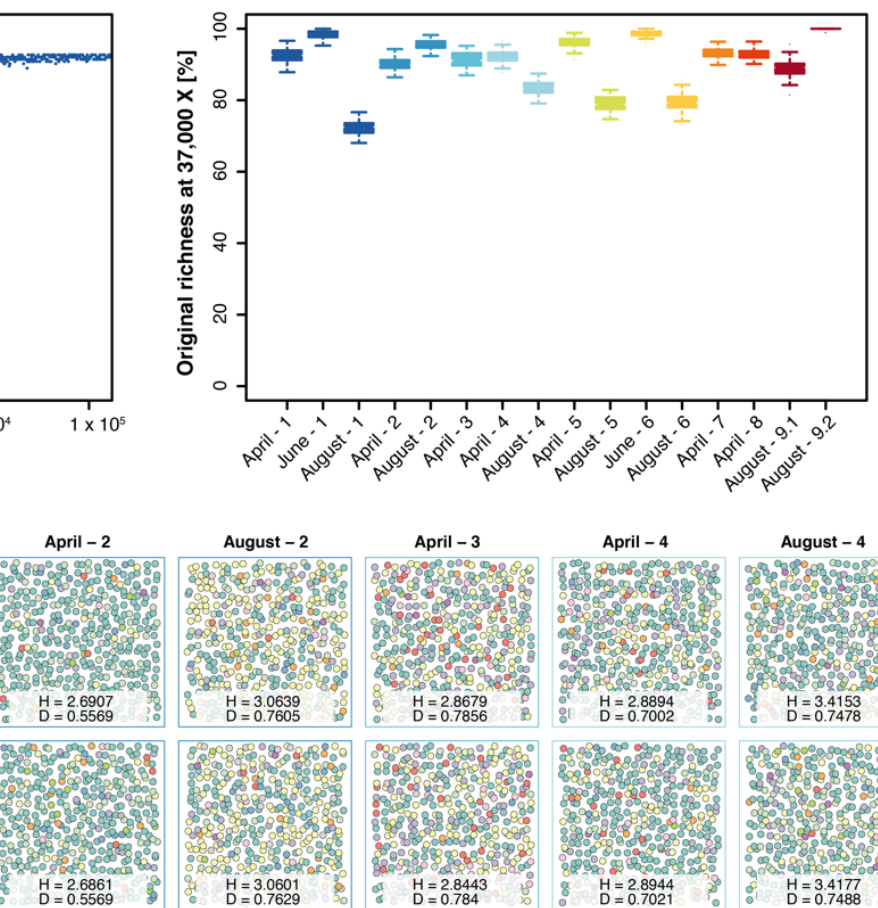

August -4
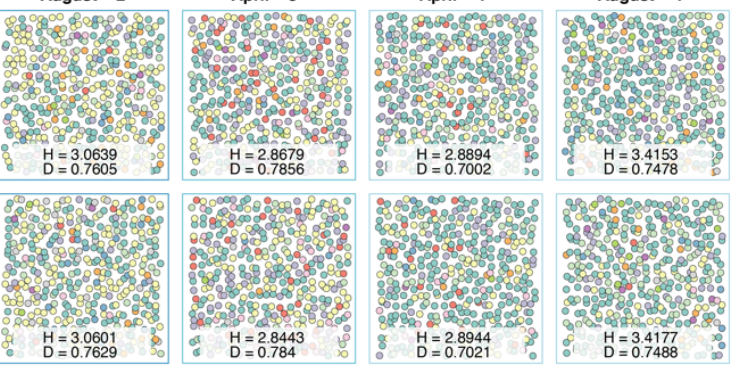

April - 7

April - 8
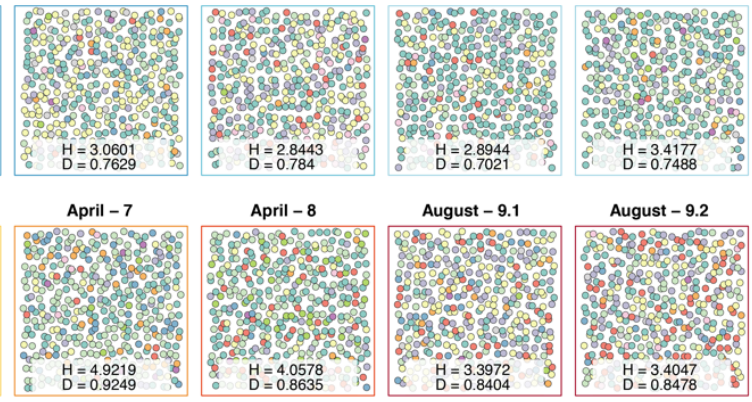

August - 9.2
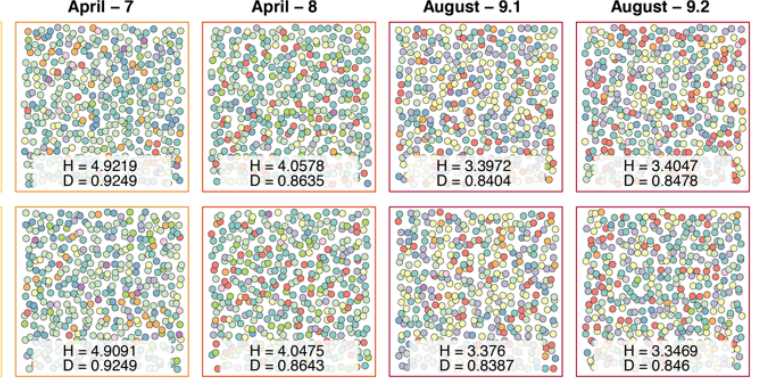

Rhodocyclaceae
Flavobacteriaceae

Microbacteriaceae Other families

Statistic

H: Shannon Entropy
D: Simpson Index

Supplementary Figure 3: Impact of rarefaction on diversity estimation. (a) Example rarefaction curve for bacterial family classifications of the 'April-1' sample. The chosen cut-off preserves most ( $90 \%)$ of the original family taxon richness (vertical line). (b) Difference between original and rarefied family richness at 37,000 reads across all freshwater sequencing runs with quantitative sequencing outputs above the chosen cut-off. Boxplots feature 100 independent rarefactions per sample. Error bars represent Q1 - 1.5*IQR (lower), and Q3 + 1.5*IQR (upper), respectively. (c) Diversity visualisation of the ten most abundant bacterial families across all samples with sequencing outputs $>37,000$ reads, through 400 'unordered bubbles'. Taxonomic proportions and colours are in accordance with Figure $3 b$. Shannon $(H)$ and Simpson (D) indices for all samples indicate marginal differences 
bioRxiv preprint doi: https://doi.org/10.1101/2020.02.06.936302; this version posted November 18, 2020. The copyright holder for this preprint (which was not certified by peer review) is the author/funder, who has granted bioRxiv a license to display the preprint in perpetuity. It is made available under aCC-BY-NC-ND 4.0 International license.

a

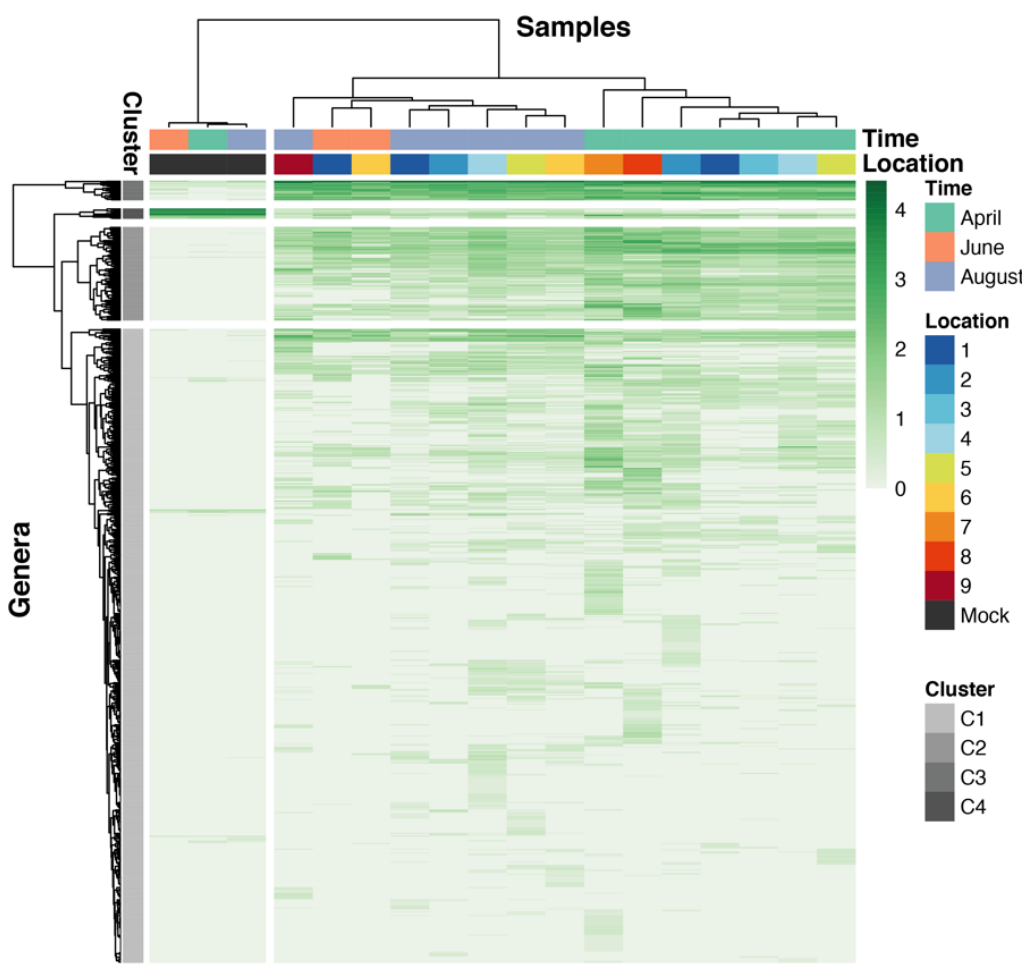

b

\begin{tabular}{ll} 
Family & Genus \\
Burkholderiaceae & Limnohabitans \\
Spirosomaceae & Pseudarcicella \\
Burkholderiaceae & Rhodoferax \\
Arcobacteraceae & Arcobacter \\
Burkholderiaceae & Polynucleobacter \\
Sphingomonadaceae & Sphingorhabdus \\
Flavobacteriaceae & Flavobacterium \\
Rhodobacteraceae & Pseudorhodobacter \\
Burkholderiaceae & Aquabacterium \\
Burkholderiaceae & Hydrogenophaga \\
Burkholderiaceae & GKS98 fw. group \\
Thiovulaceae & Sulfuricurvum \\
Burkholderiaceae & Acidovorax \\
Sphingomonadaceae & Novosphingobium \\
Xanthomonadaceae & Arenimonas \\
Crocinitomicaceae & Fluviicola \\
Microbacteriaceae & Rhodoluna \\
Rhodobacteraceae & Tabrizicola \\
Diplorickettsiaceae & Rickettsiella \\
Rhodobacteraceae & Rhodobacter \\
Sporichthyaceae & hgcl clade \\
Methylophilaceae & Methylotenera \\
Burkholderiaceae & Malikia \\
Rhodocyclaceae & Sulfuritalea \\
Sulfurospirillaceae & Sulfurospirillum \\
Burkholderiaceae & Massilia \\
Burkholderiaceae & Rhizobacter \\
\hline &
\end{tabular}

Supplementary Figure 4: River Cam core microbiome analysis on the bacterial genus level. (a) Hierarchical clustering of bacterial genera abundances across freshwater samples after rarefaction, together with the mock community control. In similarity to the family analysis displayed in Figure 4, bacterial genera are clustered into 4 groups. Two of these ( $\mathrm{C} 3$ and partially $\mathrm{C} 2)$ correspond to the core microbiome of ubiquitously abundant genera, one (C4) corresponding to the main mock community genera and one (C1) corresponding to the majority of rare accessory taxa. (b) Dominant river core microbiome on the genus level. Violin plots ( $\log _{10}$ scale of relative abundance [\%] across all samples, $\mathrm{n}_{\text {April }}=7, \mathrm{n}_{\text {une }}=2, \mathrm{n}_{\text {Augse }}=6$ ) summarise fractional representation of the top 27 bacterial genera and corresponding families from clusters $\mathrm{C} 2$ and $\mathrm{C} 3$, sorted by median total abundance. Vertical dashed line depicts $0.1 \%$ proportion. Out of the top 16 core families (Figure $4 \mathrm{~b}$ ), only the NS11-12 marine group family was found not to be represented on the genus level; NS11-12 marine group genera are mainly composed of uncultured bacteria, which here could not be classified at higher resolution. 
a
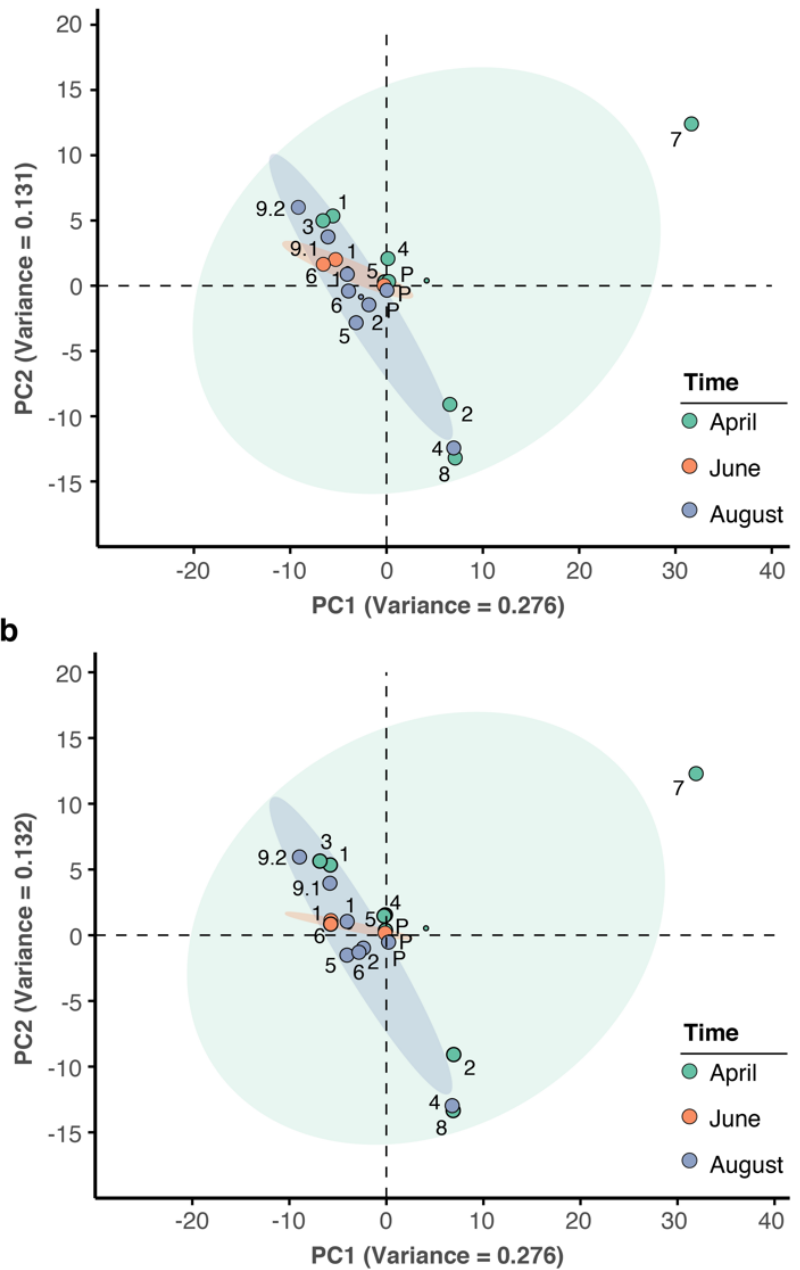
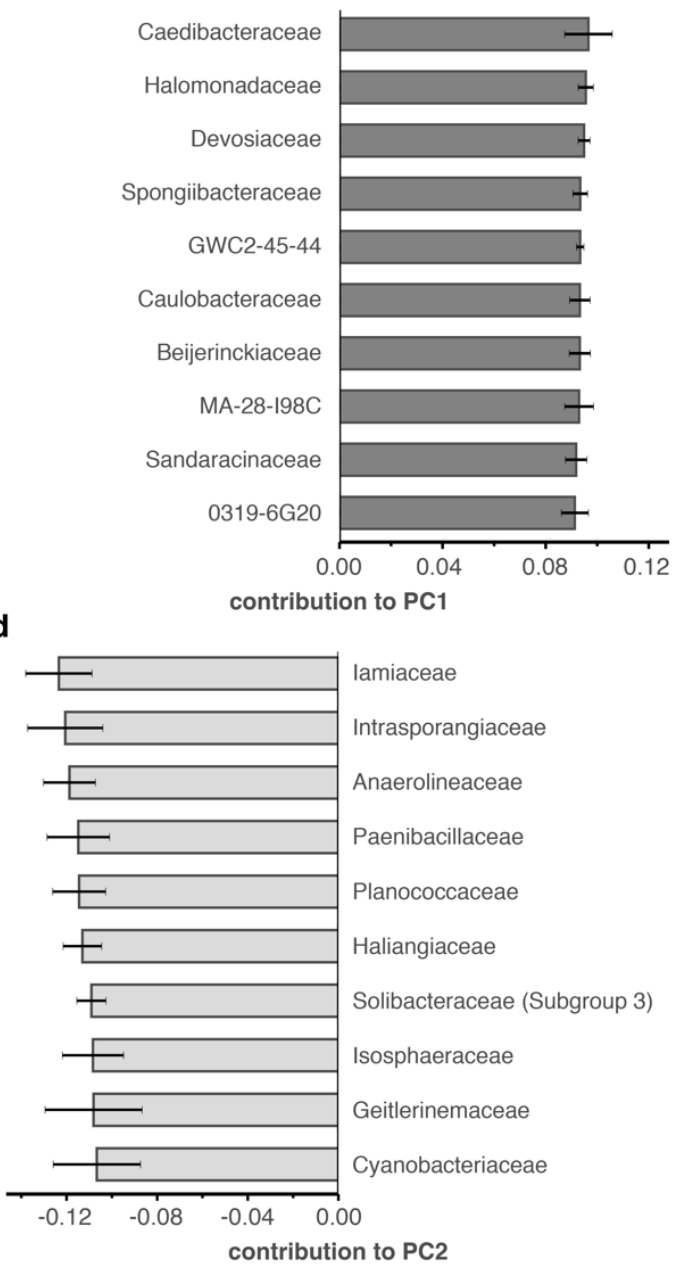

Supplementary Figure 5: Principal component analysis of river bacterial family compositions. (a-b) PCA

810 with two independent rarefaction sets to 37,000 reads in all freshwater sequencing samples. Numbers and coloured 811 dots indicate locations for each time point. The first and second principal components (PC1 and PC2, combined 812 variance: $41 \%$ ) robustly capture outlier samples 'April-7' along PC1 and 'April-2', 'August-4' and 'April-8' along 813 PC2. (c-d) Fractional loads of the ten bacterial families most strongly contributing to changes along PC1 (c) and 814 along PC2 (d). Error bars represent standard deviation of these families to the respective PC across four 815 independent rarefactions. Subsequent principal components (PC3 and PC4) are less outlier-driven and depict 816 spatial and temporal metagenomic trends within the River Cam. 
bioRxiv preprint doi: https://doi.org/10.1101/2020.02.06.936302; this version posted November 18, 2020. The copyright holder for this preprint (which was not certified by peer review) is the author/funder, who has granted bioRxiv a license to display the preprint in perpetuity. It is made available under aCC-BY-NC-ND 4.0 International license.

a

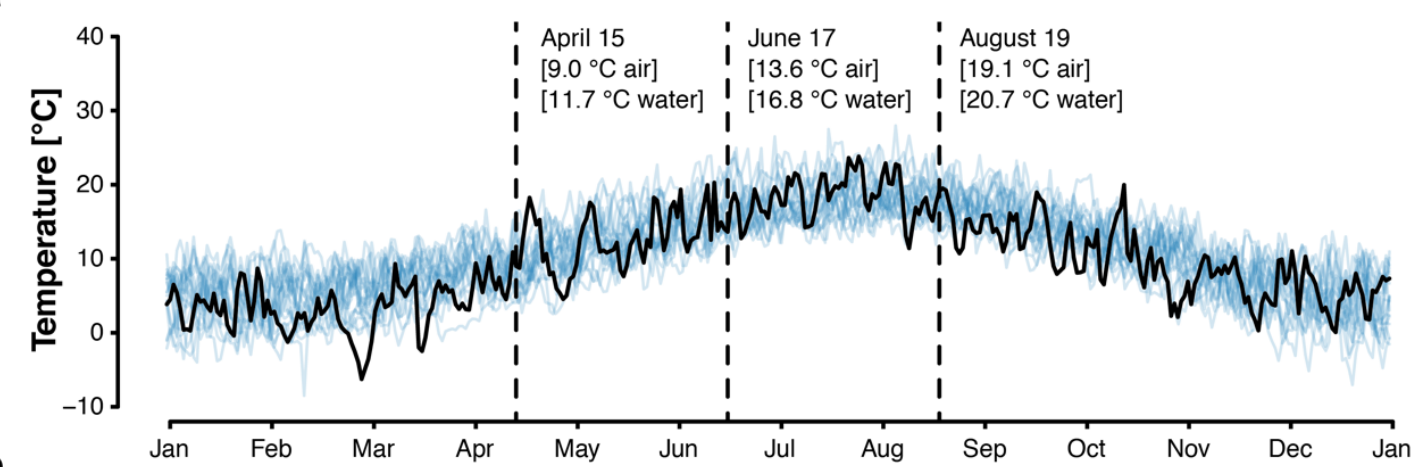

b

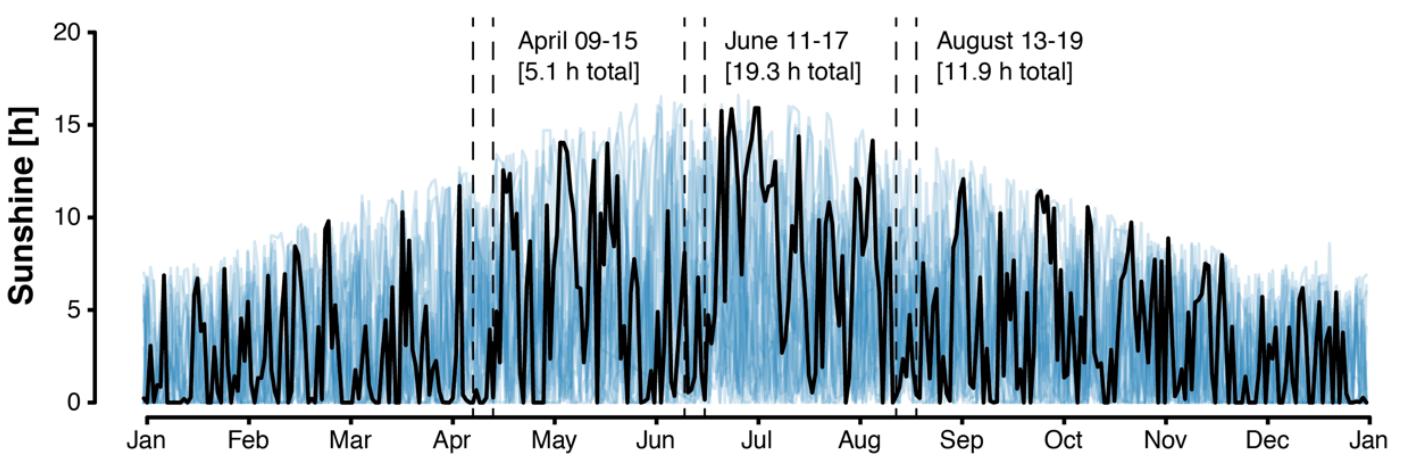

C

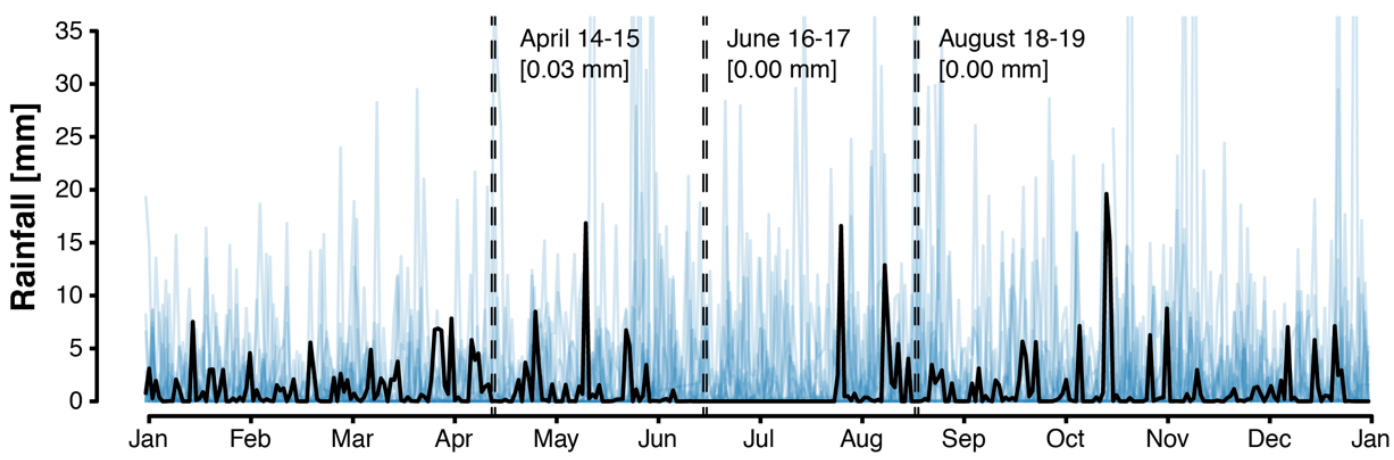

d

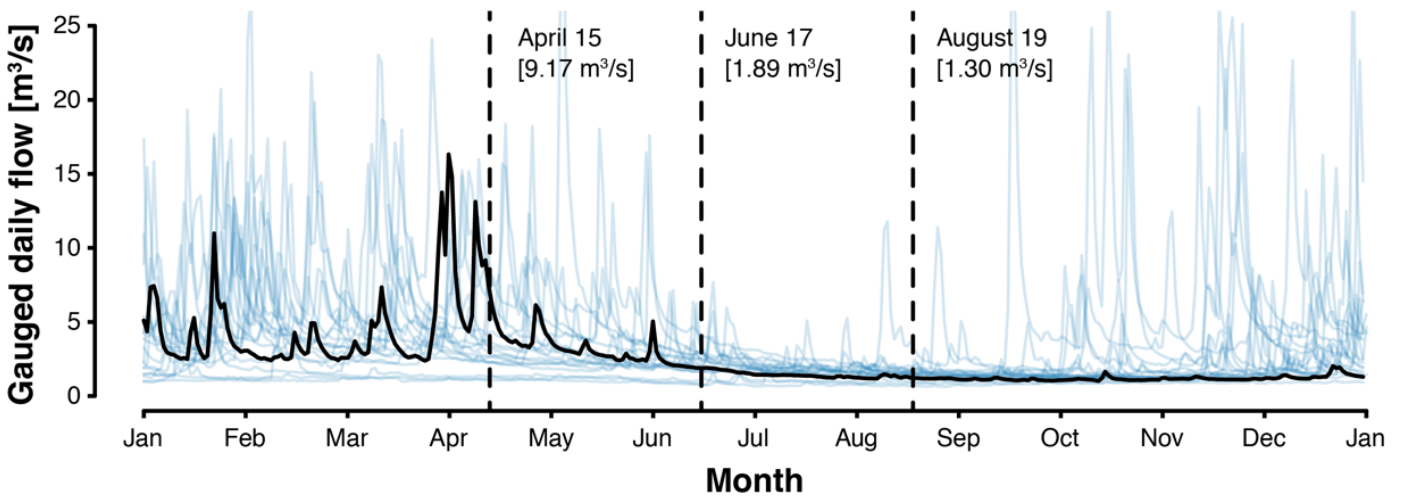

820 Supplementary Figure 6: Cambridge weather and River Cam flow rate. (a) Daily air temperature $\left[{ }^{\circ} \mathrm{C}\right]$, (b) daily sunshine [hours], and (c) daily rainfall [mm] of Cambridge in 2018 (black trend line) vs. 1998-2017 (blue background trend lines). (d) Cam River gauged daily flow $\left[\mathrm{m}^{3} \mathrm{~s}^{-1}\right]$ in 2018 (black trend line) vs. 1968-2017 (blue background trend lines). Data was compiled from public repositories https://www.cl.cam.ac.uk/research/dtg/weather/ and https://nrfa.ceh.ac.uk/. Gauged daily flow measurements at Jesus Lock, Cambridge (between sampling locations 5 and 6; NRFA \#33016) were discontinued in 1983. Yet, contemporary flow rates can be modelled with high accuracy (Pearson's $\mathrm{R}=0.9, \mathrm{R}^{2}=0.8$ ) through linear data integration of three upstream stations already in operation since before 1983: Rhee at Wimpole (NRFA \#33027, $70.2 \%$ model weight), Granta at Stapleford (NRFA \#33053, 19.6\% model weight) and Cam at Dernford (NRFA \#33024, $10.3 \%$ model weight). 
bioRxiv preprint doi: https://doi.org/10.1101/2020.02.06.936302; this version posted November 18, 2020. The copyright holder for this preprint (which was not certified by peer review) is the author/funder, who has granted bioRxiv a license to display the preprint in perpetuity. It is made available under aCC-BY-NC-ND 4.0 International license.

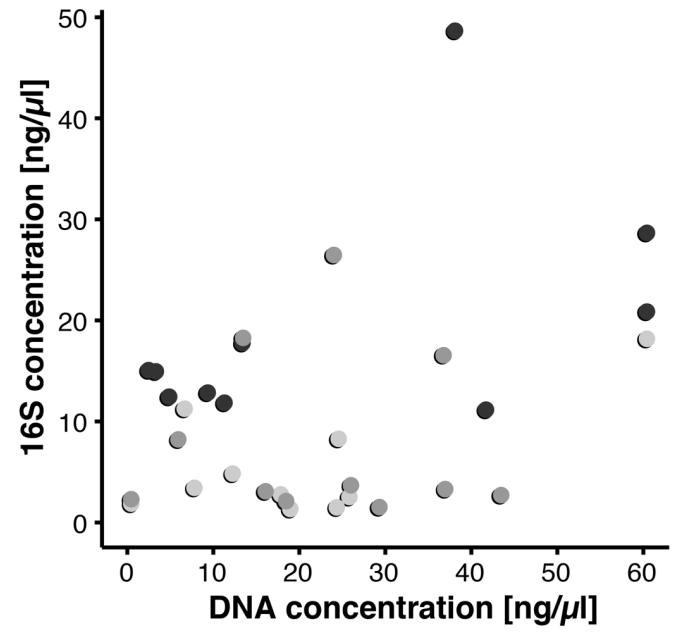

C

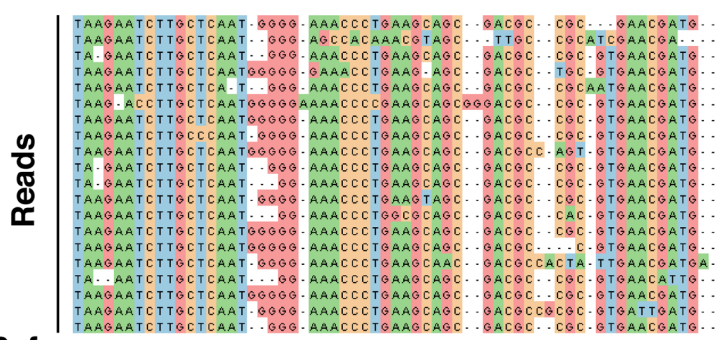

b

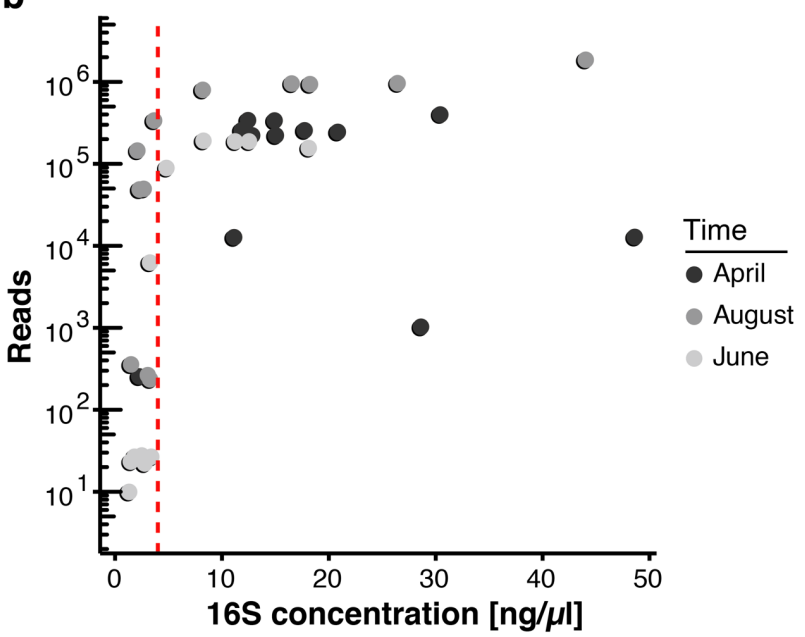

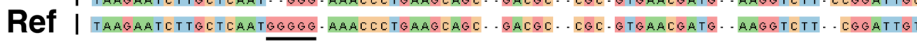

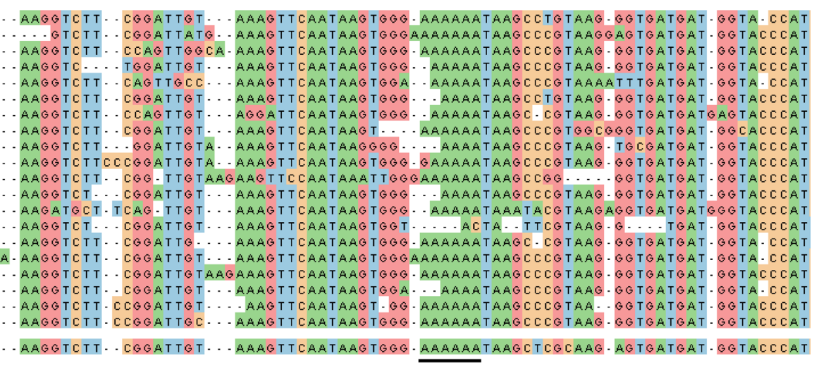

Supplementary Figure 7: Key challenges of freshwater monitoring with nanopore sequencing. (a-b) Correlation analysis between DNA extraction yield, $16 \mathrm{~S}$ amplification yield and raw sequencing output (Supplementary Table 2). (a) DNA concentrations (x-axis) obtained from 30 freshwater samples after extraction with the DNeasy PowerWater Kit (Material and Methods) are compared against the DNA concentration of the same samples after full-length 16S PCR amplification (y-axis), as measured by Qubit dsDNA HS. (b) The DNA concentration obtained for each sample after full-length 16S PCR amplification (x-axis) is compared against the final number of demultiplexed nanopore sequencing reads. Samples with a minimum input concentration measurement of $\sim 5 \mathrm{ng} / \mu 1$ yielded sequencing outputs sufficient to pass the rarefaction threshold of 37,000 reads. (c) Multiple sequence alignment of an example set of related nanopore $16 \mathrm{~S}$ sequences, displaying increased indel rates at homopolymer reference sites (underlined); the mean sequencing error rate for this study lies at $7.92 \%$. 


\section{SUPPLEMENTARY TABLE LEGENDS}

853 Table S1: Summary of samples and metadata. (a) Sampling locations. (b) Environmental metadata by sample. (c)

854 Environmental metadata by time point.

855

856

Table S2: Summary of raw DNA, amplicon and sequencing yields. (a) Water DNA extraction yields. (b) Full-

857

858 length 16S PCR amplicon extraction yields. (c) Nanopore sequencing read metrics.

859 Table S3: Summary of pathogen and wastewater bacterial genera tested. (a-b) List of pathogen (a) and wastewater

860 (b) candidate bacterial genera.

861

862

863

864

865

866

867

868

869

870

871

872

873

874

875

Table S4: Summary of reference sequences for high-resolution pathogen mapping. (a-d) References and NCBI accessions for Legionella (a), Salmonella (b), Pseudomonas (c) and Leptospira (d).

Table S5: Summary of multi-species Leptospira quantifications by Taqman qPCR.

Table S6: Summary of project costs. (a) Basic sequencing workflow cost estimate. (b) Cost estimate per sample, based on a 12-plex MinION sequencing run. (c) Projected cost estimate per sample, based on a 100-plex MinION sequencing run.

Table S7: Summary of full-length $16 \mathrm{~S}$ primer sequences $\left(5^{\prime}-3^{\prime}\right)$.

Table S8: Summary of negative controls. (a-c) Relative classification output per sample (\%), sorted by negative control abundances in April (a), June (b) and August (c). 
Acharya, K., Khanal, S., Pantha, K., Amatya, N., Davenport, R. J., \& Werner, D. (2019). A comparative assessment of conventional and molecular methods, including MinION nanopore sequencing, for surveying water quality. Sci Rep, 9(1), 15726. doi:10.1038/s41598-019-51997-x

896

Allard, G., Ryan, F. J., Jeffery, I. B., \& Claesson, M. J. (2015). SPINGO: a rapid species-classifier for microbial amplicon sequences. BMC Bioinformatics, 16, 324. doi:10.1186/s12859-015-0747-1

Almeida, A., Mitchell, A. L., Boland, M., Forster, S. C., Gloor, G. B., Tarkowska, A., . . Finn, R. D. (2019). A new genomic blueprint of the human gut microbiota. Nature, 568(7753), 499-504. doi:10.1038/s41586019-0965-1

Altschul, S. F., Gish, W., Miller, W., Myers, E. W., \& Lipman, D. J. (1990). Basic local alignment search tool.

903 Journal of Molecular Biology, 215(3), 403-410. doi:10.1016/S0022-2836(05)80360-2

Bahram, M., Hildebrand, F., Forslund, S. K., Anderson, J. L., Soudzilovskaia, N. A., Bodegom, P. M., . . Bork, P. (2018). Structure and function of the global topsoil microbiome. Nature, 560(7717), 233-237. doi:10.1038/s41586-018-0386-6

Bartram, J., Lewis, K., Lenton, R., \& Wright, A. (2005). Focusing on improved water and sanitation for health. The Lancet, 365(9461), 810-812. doi:10.1016/s0140-6736(05)17991-4

Benitez-Paez, A., Portune, K. J., \& Sanz, Y. (2016). Species-level resolution of 16S rRNA gene amplicons sequenced through the MinION portable nanopore sequencer. Gigascience, 5, 4. doi:10.1186/s13742016-0111-z

Bolyen, E., Rideout, J. R., Dillon, M. R., Bokulich, N. A., Abnet, C. C., Al-Ghalith, G. A., . . Caporaso, J. G. (2019). Reproducible, interactive, scalable and extensible microbiome data science using QIIME 2. Nat Biotechnol, 37(8), 852-857. doi:10.1038/s41587-019-0209-9

Boykin, L. M., Sseruwagi, P., Alicai, T., Ateka, E., Mohammed, I. U., Stanton, J. L., . . Ndunguru, J. (2019). Tree Lab: Portable genomics for Early Detection of Plant Viruses and Pests in Sub-Saharan Africa. Genes (Basel), 10(9). doi:10.3390/genes10090632

Callahan, B. J., McMurdie, P. J., Rosen, M. J., Han, A. W., Johnson, A. J., \& Holmes, S. P. (2016). DADA2: High-resolution sample inference from Illumina amplicon data. Nat Methods, 13(7), 581-583. doi: $10.1038 /$ nmeth.3869

Calus, S. T., Ijaz, U. Z., \& Pinto, A. J. (2018). NanoAmpli-Seq: a workflow for amplicon sequencing for mixed microbial communities on the nanopore sequencing platform. Gigascience, 7(12). doi:10.1093/gigascience/giy140

Camacho, C., Coulouris, G., Avagyan, V., Ma, N., Papadopoulos, J., Bealer, K., \& Madden, T. L. (2009). BLAST+: architecture and applications. BMC Bioinformatics, 10, 421. doi:10.1186/1471-2105-10-421

Chan, J. F.-W., Yuan, S., Kok, K.-H., To, K. K.-W., Chu, H., Yang, J., , . Yuen, K.-Y. (2020). A familial cluster of pneumonia associated with the 2019 novel coronavirus indicating person-to-person transmission: a study of a family cluster. The Lancet. doi:10.1016/s0140-6736(20)30154-9 using Nanopore sequencing: full-length 16S rRNA gene and the 16S-ITS-23S of the rrn operon. F1000Res, 7, 1755. doi:10.12688/f1000research.16817.2

Darby, B. J., Todd, T. C., \& Herman, M. A. (2013). High-throughput amplicon sequencing of rRNA genes requires a copy number correction to accurately reflect the effects of management practices on soil nematode community structure. Mol Ecol, 22(21), 5456-5471. doi:10.1111/mec.12480 
bioRxiv preprint doi: https://doi.org/10.1101/2020.02.06.936302; this version posted November 18, 2020. The copyright holder for this preprint (which was not certified by peer review) is the author/funder, who has granted bioRxiv a license to display the preprint in perpetuity. It is made available under aCC-BY-NC-ND 4.0 International license.

Edgar, R. C. (2016). SINTAX: a simple non-Bayesian taxonomy classifier for 16S and ITS sequences. bioRxiv, 074161. doi:10.1101/074161

Faria, N. R., Kraemer, M. U. G., Hill, S. C., Goes de Jesus, J., Aguiar, R. S., Iani, F. C. M., . . Pybus, O. G. (2018). Genomic and epidemiological monitoring of yellow fever virus transmission potential. Science, 361(6405), 894. doi:10.1126/science.aat7115

Faria, N. R., Quick, J., Claro, I. M., Theze, J., de Jesus, J. G., Giovanetti, M., . . Pybus, O. G. (2017). Establishment and cryptic transmission of Zika virus in Brazil and the Americas. Nature, 546(7658), 406-410. doi:10.1038/nature22401

Fisher, J. C., Newton, R. J., Dila, D. K., \& McLellan, S. L. (2015). Urban microbial ecology of a freshwater estuary of Lake Michigan. Elementa (Wash D C), 3. doi:10.12952/journal.elementa.000064

Frank, J. A., Reich, C. I., Sharma, S., Weisbaum, J. S., Wilson, B. A., \& Olsen, G. J. (2008). Critical evaluation of two primers commonly used for amplification of bacterial 16S rRNA genes. Appl Environ Microbiol, 74(8), 2461-2470. doi:10.1128/AEM.02272-07

Gaillardet, J., Dupré, B., Louvat, P., \& Allègre, C. J. (1999). Global silicate weathering and CO2 consumption rates deduced from the chemistry of large rivers. Chemical Geology, 159(1), 3-30. doi:10.1016/S00092541(99)00031-5

Ganoza, C. A., Matthias, M. A., Collins-Richards, D., Brouwer, K. C., Cunningham, C. B., Segura, E. R., . . Vinetz, J. M. (2006). Determining risk for severe leptospirosis by molecular analysis of environmental surface waters for pathogenic Leptospira. PLoS Med, 3(8), e308. doi:10.1371/journal.pmed.0030308

Gardy, J. L., \& Loman, N. J. (2018). Towards a genomics-informed, real-time, global pathogen surveillance system. Nat Rev Genet, 19(1), 9-20. doi:10.1038/nrg.2017.88

Gowers, G. F., Vince, O., Charles, J. H., Klarenberg, I., Ellis, T., \& Edwards, A. (2019). Entirely Off-Grid and Solar-Powered DNA Sequencing of Microbial Communities during an Ice Cap Traverse Expedition. Genes (Basel), 10(11). doi:10.3390/genes10110902

Haddeland, I., Heinke, J., Biemans, H., Eisner, S., Florke, M., Hanasaki, N., . . Wisser, D. (2014). Global water resources affected by human interventions and climate change. Proc Natl Acad Sci U S A, 111(9), 3251-3256. doi:10.1073/pnas.1222475110

Hamner, S., Brown, B. L., Hasan, N. A., Franklin, M. J., Doyle, J., Eggers, M. J., . . Ford, T. E. (2019). Metagenomic Profiling of Microbial Pathogens in the Little Bighorn River, Montana. Int J Environ Res Public Health, 16(7). doi:10.3390/ijerph16071097

Jain, M., Olsen, H. E., Paten, B., \& Akeson, M. (2016). The Oxford Nanopore MinION: delivery of nanopore sequencing to the genomics community. Genome Biol, 17(1), 239. doi:10.1186/s13059-016-1103-0

Jin, D., Kong, X., Cui, B., Jin, S., Xie, Y., Wang, X., \& Deng, Y. (2018). Bacterial communities and potential waterborne pathogens within the typical urban surface waters. Sci Rep, 8(1), 13368. doi:10.1038/s41598-018-31706-w

Kafetzopoulou, L. E., Pullan, S. T., Lemey, P., Suchard, M. A., Ehichioya, D. U., Pahlmann, M., .. . Duraffour, S. (2019). Metagenomic sequencing at the epicenter of the Nigeria 2018 Lassa fever outbreak. Science, 363(6422), 74. doi:10.1126/science.aau9343

Karst, S. M., Ziels, R. M., Kirkegaard, R. H., Sørensen, E. A., McDonald, D., Zhu, Q., . . Albertsen, M. (2020). Enabling high-accuracy long-read amplicon sequences using unique molecular identifiers with Nanopore or PacBio sequencing. bioRxiv, 645903. doi:10.1101/645903

Kayman, T., Abay, S., Hizlisoy, H., Atabay, H. I., Diker, K. S., \& Aydin, F. (2012). Emerging pathogen Arcobacter spp. in acute gastroenteritis: molecular identification, antibiotic susceptibilities and genotyping of the isolated arcobacters. J Med Microbiol, 61(Pt 10), 1439-1444. doi:10.1099/jmm.0.044594-0 
bioRxiv preprint doi: https://doi.org/10.1101/2020.02.06.936302; this version posted November 18, 2020. The copyright holder for this preprint (which was not certified by peer review) is the author/funder, who has granted bioRxiv a license to display the preprint in perpetuity. It is made available under aCC-BY-NC-ND 4.0 International license.

982

983

984

985

986

987

988

989

990

991

992

993

994

995

996

997

998

999

1000

1001

1002

1003

1004

1005

1006

1007

1008

1009

1010

1011

1012

1013

1014

1015

1016

1017

1018

1019

1020

1021

1022

Kerkhof, L. J., Dillon, K. P., Haggblom, M. M., \& McGuinness, L. R. (2017). Profiling bacterial communities by MinION sequencing of ribosomal operons. Microbiome, 5(1), 116. doi:10.1186/s40168-017-0336-9

Kim, D., Song, L., Breitwieser, F. P., \& Salzberg, S. L. (2016). Centrifuge: rapid and sensitive classification of metagenomic sequences. Genome Res, 26(12), 1721-1729. doi:10.1101/gr.210641.116

Köster, J., \& Rahmann, S. (2012). Snakemake--a scalable bioinformatics workflow engine. Bioinformatics, 28(19), 2520-2522. doi:10.1093/bioinformatics/bts480

Kovaka, S., Fan, Y., Ni, B., Timp, W., \& Schatz, M. C. (2020). Targeted nanopore sequencing by real-time mapping of raw electrical signal with UNCALLED. bioRxiv, 2020.2002.2003.931923. doi:10.1101/2020.02.03.931923

Latorre-Perez, A., Villalba-Bermell, P., Pascual, J., \& Vilanova, C. (2020). Assembly methods for nanoporebased metagenomic sequencing: a comparative study. Sci Rep, 10(1), 13588. doi:10.1038/s41598-02070491-3

Lawson, P. A., \& Caldwell, M. E. (2014). The Family Carnobacteriaceae. In The Prokaryotes (pp. 19-65). Berlin, Heidelberg: Springer Berlin Heidelberg.

Leggett, R. M., Alcon-Giner, C., Heavens, D., Caim, S., Brook, T. C., Kujawska, M., . . Clark, M. D. (2019). Rapid MinION profiling of preterm microbiota and antimicrobial-resistant pathogens. Nat Microbiol. doi:10.1038/s41564-019-0626-z

Li, H. (2018). Minimap2: pairwise alignment for nucleotide sequences. Bioinformatics, 34(18), 3094-3100. doi:10.1093/bioinformatics/bty191

Li, H., Handsaker, B., Wysoker, A., Fennell, T., Ruan, J., Homer, N., . . Genome Project Data Processing, S. (2009). The Sequence Alignment/Map format and SAMtools. Bioinformatics, 25(16), 2078-2079. doi:10.1093/bioinformatics/btp352

Loose, M., Malla, S., \& Stout, M. (2016). Real-time selective sequencing using nanopore technology. Nat Methods, 13(9), 751-754. doi:10.1038/nmeth.3930

Matias Rodrigues, J. F., Schmidt, T. S. B., Tackmann, J., \& von Mering, C. (2017). MAPseq: highly efficient kmer search with confidence estimates, for rRNA sequence analysis. Bioinformatics, 33(23), 3808-3810. doi:10.1093/bioinformatics/btx517

Morgulis, A., Coulouris, G., Raytselis, Y., Madden, T. L., Agarwala, R., \& Schaffer, A. A. (2008). Database indexing for production MegaBLAST searches. Bioinformatics, 24(16), 1757-1764. doi:10.1093/bioinformatics/btn322

Murali, A., Bhargava, A., \& Wright, E. S. (2018). IDTAXA: a novel approach for accurate taxonomic classification of microbiome sequences. Microbiome, 6(1), 140. doi:10.1186/s40168-018-0521-5

Nicholls, S. M., Quick, J. C., Tang, S., \& Loman, N. J. (2019). Ultra-deep, long-read nanopore sequencing of mock microbial community standards. Gigascience, 8(5). doi:10.1093/gigascience/giz043

Nielsen, P. H., Saunders, A. M., Hansen, A. A., Larsen, P., \& Nielsen, J. L. (2012). Microbial communities involved in enhanced biological phosphorus removal from wastewater--a model system in environmental biotechnology. Curr Opin Biotechnol, 23(3), 452-459. doi:10.1016/j.copbio.2011.11.027

Numberger, D., Ganzert, L., Zoccarato, L., Muhldorfer, K., Sauer, S., Grossart, H. P., \& Greenwood, A. D. (2019). Characterization of bacterial communities in wastewater with enhanced taxonomic resolution by full-length 16S rRNA sequencing. Sci Rep, 9(1), 9673. doi:10.1038/s41598-019-46015-z 
bioRxiv preprint doi: https://doi.org/10.1101/2020.02.06.936302; this version posted November 18, 2020. The copyright holder for this preprint (which was not certified by peer review) is the author/funder, who has granted bioRxiv a license to display the preprint in perpetuity. It is made available under aCC-BY-NC-ND 4.0 International license.

Nygaard, A. B., Tunsjo, H. S., Meisal, R., \& Charnock, C. (2020). A preliminary study on the potential of Nanopore MinION and Illumina MiSeq 16S rRNA gene sequencing to characterize building-dust microbiomes. Sci Rep, 10(1), 3209. doi:10.1038/s41598-020-59771-0

Paulson, J. N., Stine, O. C., Bravo, H. C., \& Pop, M. (2013). Differential abundance analysis for microbial marker-gene surveys. Nat Methods, 10(12), 1200-1202. doi:10.1038/nmeth.2658

Payne, A., Holmes, N., Clarke, T., Munro, R., Debebe, B., \& Loose, M. (2020). Nanopore adaptive sequencing for mixed samples, whole exome capture and targeted panels. bioRxiv, 2020.2002.2003.926956. doi:10.1101/2020.02.03.926956

Payne, A., Holmes, N., Rakyan, V., \& Loose, M. (2018). Whale watching with BulkVis: A graphical viewer for Oxford Nanopore bulk fast5 files. bioRxiv. doi:10.1101/312256

Prüss-Üstün, A., Kay, D., Fewtrell, L., \& Bartram, J. (2002). Estimating the burden of disease from water, sanitation, and hygiene at a global level. Environmental Health Perspectives, 110(5), 537-542. doi:10.1289/ehp.110-1240845

Prüss-Üstün, A., Wolf, J., Bartram, J., Clasen, T., Cumming, O., Freeman, M. C., . . Johnston, R. (2019). Burden of disease from inadequate water, sanitation and hygiene for selected adverse health outcomes: An updated analysis with a focus on low- and middle-income countries. Int J Hyg Environ Health, 222(5), 765-777. doi:10.1016/j.ijheh.2019.05.004

Public Health England. (2016). Pilot study to improve the surveillance of laboratory-confirmed cases of leptospirosis. Leptospirosis Enhanced Surveillance Protocol.

Public Health England. (2019). Common animal-associated infections (England and Wales): fourth quarter 2019. Health Protection Report.

Quast, C., Pruesse, E., Yilmaz, P., Gerken, J., Schweer, T., Yarza, P., . . Glockner, F. O. (2013). The SILVA ribosomal RNA gene database project: improved data processing and web-based tools. Nucleic Acids Res, 41(Database issue), D590-596. doi:10.1093/nar/gks1219

Quick, J., Ashton, P., Calus, S., Chatt, C., Gossain, S., Hawker, J., . . Loman, N. J. (2015). Rapid draft sequencing and real-time nanopore sequencing in a hospital outbreak of Salmonella. Genome Biol, 16, 114. doi:10.1186/s13059-015-0677-2

Quick, J., Loman, N. J., Duraffour, S., Simpson, J. T., Severi, E., Cowley, L., . . Carroll, M. W. (2016). Realtime, portable genome sequencing for Ebola surveillance. Nature, 530(7589), 228-232. doi:10.1038/nature16996

Ramirez-Castillo, F. Y., Loera-Muro, A., Jacques, M., Garneau, P., Avelar-Gonzalez, F. J., Harel, J., \& Guerrero-Barrera, A. L. (2015). Waterborne pathogens: detection methods and challenges. Pathogens, 4(2), 307-334. doi:10.3390/pathogens4020307

Rang, F. J., Kloosterman, W. P., \& de Ridder, J. (2018). From squiggle to basepair: computational approaches for improving nanopore sequencing read accuracy. Genome Biol, 19(1), 90. doi:10.1186/s13059-018$1462-9$

Reddington, K., Eccles, D., O'Grady, J., Drown, D. M., Hansen, L. H., Nielsen, T. K., . . . Brown, B. L. (2020). Metagenomic analysis of planktonic riverine microbial consortia using nanopore sequencing reveals insight into river microbe taxonomy and function. Gigascience, 9(6). doi:10.1093/gigascience/giaa053

Rognes, T., Flouri, T., Nichols, B., Quince, C., \& Mahe, F. (2016). VSEARCH: a versatile open source tool for metagenomics. PeerJ, 4, e2584. doi:10.7717/peerj.2584

Rose, S. (2007). The effects of urbanization on the hydrochemistry of base flow within the Chattahoochee River Basin (Georgia, USA). Journal of Hydrology, 341(1-2), 42-54. doi:10.1016/j.jhydrol.2007.04.019 
bioRxiv preprint doi: https://doi.org/10.1101/2020.02.06.936302; this version posted November 18, 2020. The copyright holder for this preprint (which was not certified by peer review) is the author/funder, who has granted bioRxiv a license to display the preprint in perpetuity. It is made available under aCC-BY-NC-ND 4.0 International license.

1066

Rowe, W., Baker-Austin, C., Verner-Jeffreys, D. W., Ryan, J. J., Micallef, C., Maskell, D. J., \& Pearce, G. P. (2017). Overexpression of antibiotic resistance genes in hospital effluents over time. J Antimicrob Chemother, 72(6), 1617-1623. doi:10.1093/jac/dkx017

Rowe, W., Verner-Jeffreys, D. W., Baker-Austin, C., Ryan, J. J., Maskell, D. J., \& Pearce, G. P. (2016). Comparative metagenomics reveals a diverse range of antimicrobial resistance genes in effluents entering a river catchment. Water Sci Technol, 73(7), 1541-1549. doi:10.2166/wst.2015.634

Salazar, G., \& Sunagawa, S. (2017). Marine microbial diversity. Curr Biol, 27(11), R489-R494. doi:10.1016/j.cub.2017.01.017

Salter, S. J., Cox, M. J., Turek, E. M., Calus, S. T., Cookson, W. O., Moffatt, M. F., .. W Walker, A. W. (2014). Reagent and laboratory contamination can critically impact sequence-based microbiome analyses. BMC Biology, 12(1), 87. doi:10.1186/s12915-014-0087-z

Santos, A., van Aerle, R., Barrientos, L., \& Martinez-Urtaza, J. (2020). Computational methods for 16S metabarcoding studies using Nanopore sequencing data. Comput Struct Biotechnol J, 18, 296-305. doi:10.1016/j.csbj.2020.01.005

Schewe, J., Heinke, J., Gerten, D., Haddeland, I., Arnell, N. W., Clark, D. B., . . Kabat, P. (2014). Multimodel assessment of water scarcity under climate change. Proc Natl Acad Sci U S A, 111(9), 3245-3250. doi:10.1073/pnas.1222460110

Schloss, P. D., Westcott, S. L., Ryabin, T., Hall, J. R., Hartmann, M., Hollister, E. B., . . Weber, C. F. (2009). Introducing mothur: open-source, platform-independent, community-supported software for describing and comparing microbial communities. Appl Environ Microbiol, 75(23), 7537-7541. doi:10.1128/AEM.01541-09

Stewart, R. D., Auffret, M. D., Warr, A., Walker, A. W., Roehe, R., \& Watson, M. (2019). Compendium of 4,941 rumen metagenome-assembled genomes for rumen microbiome biology and enzyme discovery. Nat Biotechnol, 37(8), 953-961. doi:10.1038/s41587-019-0202-3

Sunagawa, S., Coelho, L. P., Chaffron, S., Kultima, J. R., Labadie, K., Salazar, G., .. . Bork, P. (2015). Structure and function of the global ocean microbiome. Science, 348(6237).

Tan, B., Ng, C., Nshimyimana, J. P., Loh, L. L., Gin, K. Y., \& Thompson, J. R. (2015). Next-generation sequencing (NGS) for assessment of microbial water quality: current progress, challenges, and future opportunities. Front Microbiol, 6, 1027. doi:10.3389/fmicb.2015.01027

Tringe, S. G., \& Rubin, E. M. (2005). Metagenomics: DNA sequencing of environmental samples. Nat Rev Genet, 6(11), 805-814. doi:10.1038/nrg1709

Vincent, A. T., Schiettekatte, O., Goarant, C., Neela, V. K., Bernet, E., Thibeaux, R., . . Picardeau, M. (2019). Revisiting the taxonomy and evolution of pathogenicity of the genus Leptospira through the prism of genomics. PLoS Negl Trop Dis, 13(5), e0007270. doi:10.1371/journal.pntd.0007270

Wang, Q., Garrity, G. M., Tiedje, J. M., \& Cole, J. R. (2007). Naive Bayesian classifier for rapid assignment of rRNA sequences into the new bacterial taxonomy. Appl Environ Microbiol, 73(16), 5261-5267. doi:10.1128/AEM.00062-07

Wattam, A. R., Davis, J. J., Assaf, R., Boisvert, S., Brettin, T., Bun, C., . . Stevens, R. L. (2017). Improvements to PATRIC, the all-bacterial Bioinformatics Database and Analysis Resource Center. Nucleic Acids Res, 45(D1), D535-D542. doi:10.1093/nar/gkw1017

Wick, R. R., Judd, L. M., \& Holt, K. E. (2019). Performance of neural network basecalling tools for Oxford Nanopore sequencing. Genome Biol, 20(1), 129. doi:10.1186/s13059-019-1727-y

Wood, D. E., Lu, J., \& Langmead, B. (2019). Improved metagenomic analysis with Kraken 2. Genome Biol, 20(1), 257. doi:10.1186/s13059-019-1891-0 
1110 Wood, D. E., \& Salzberg, S. L. (2014). Kraken: ultrafast metagenomic sequence classification using exact alignments. Genome Biology, 15(3), R46. doi:10.1186/gb-2014-15-3-r46

1112 Wright, E. S. (2016). Using DECIPHER v2.0 to Analyze Big Biological Sequence Data in R. The R Journal, 1113 8(1), 352-359.

1114 Wu, L., Ning, D., Zhang, B., Li, Y., Zhang, P., Shan, X., . . Zhou, J. (2019). Global diversity and biogeography of bacterial communities in wastewater treatment plants. Nat Microbiol, 4(7), 1183-1195.

1116 doi:10.1038/s41564-019-0426-5

1117 Wynwood, S. J., Graham, G. C., Weier, S. L., Collet, T. A., McKay, D. B., \& Craig, S. B. (2014). Leptospirosis from water sources. Pathogens and Global Health, 108(7), 334-338.

1119 doi:10.1179/2047773214Y.0000000156 